\title{
O EFEITO DA INFORMAÇÃO DE SUSTENTABILIDADE CORPORATIVA NOS RETORNOS DAS AÇÕES: análise de empresas incluídas no ranking Global 100
}

1- Nathállya Etyenne Figueira Silva*

Mestre em Administração pela Universidade Federal da Paraíba (UFPB), Brasil.

Professora do Centro Universitário de João Pessoa (UNIPÊ), Brasil.

nathallyaetyenne@gmail.com

http://lattes.cnpq.br/2822546564690021

2- Aldo Leonardo Cunha Callado

Doutor em Agronegócios pela Universidade Federal do Rio Grande do Sul (UFRGS), Brasil.

Professor do Departamento de Finanças e Contabilidade da Universidade Federal da Paraíba (UFPB), Brasil. aldocallado@yahoo.com.br

http://lattes.cnpq.br/2210545587344776

\author{
Diego Maganhotto Coraiola - Editor Geral \\ Editor responsável pela submissão: \\ Diego Maganhotto Coraiola.
}

Artigo analisado via processo de revisão duplo cego (Double-blind).

Recebido em: 15/05/2017

Aprovado em: 26/08/2017

última Alteração: 09/09/2017

* Contato Principal: Rua Comerciante José Raimundo Calado, no136. Água Fria - João Pessoa - PB, Brasil. CEP: 58053-026. 


\section{O EFEITO DA INFORMAÇÃO DE SUSTENTABILIDADE CORPORATIVA NOS RETORNOS DAS AÇÕES: ANÁLISE DE EMPRESAS INCLUÍDAS NO RANKING GLOBAL $100^{1}$}

\section{RESUMO}

Esta pesquisa buscou analisar o efeito causado nos retornos das ações das empresas após a divulgação de inclusão no ranking Global 100. Para tanto, utilizou-se a metodologia de Estudo de Eventos, na qual se baseia na hipótese de mercado eficiente semiforte. Foram considerados os rankings Global 100 divulgados ao longo de 12 anos, de 2005 até 2016. A amostra da pesquisa foi constituída por ações das empresas que dispunham de dados na data de sua respectiva inclusão, sendo assim composta por 266 ações. A variável utilizada foram as cotações diárias das ações das empresas durante o período de estimação (160 dias) e janela de evento (21 dias) e dos índices de mercado dos países em que a ação foi cotada, coletadas no Banco de Dados da Thomson Reuters $\AA_{\text {. }}$ Os resultados obtidos apresentaram que a divulgação do ranking Global 100 não causou efeito positivo ou negativo significante nos retornos anormais acumulados (CARs) das ações das empresas incluídas.

\section{Palavras-Chave}

Global 100; Responsabilidade social corporativa; Sustentabilidade; Desempenho financeiro.

\section{THE EFFECT OF CORPORATE SUSTAINABILITY INFORMATION ON SHARE RETURNS: ANALYSIS OF COMPANIES INCLUDED IN THE GLOBAL RANKING 100}

\section{ABSTRACT}

This study aimed to analyze the effect of corporate returns after the disclosure of inclusion in the Global 100 ranking. For this purpose, the methodology of the Study of Events was used, based on the hypothesis of a semi-strong efficient market. The Global 100 rankings considered in this study were the ones released over 12 years, from 2005 to 2016. The survey sample composed of the shares of the companies that had data on the date of their inclusion, and thus consisting of 266 shares. The variable used was daily quotations of companies' shares during the estimation period (160 days) and event window (21 days) and the market indices of the countries in which the share was quoted, collected in the Thomson Reuters Database ${ }^{\circledR}$. The results showed that the release of the Global 100 ranking did not cause significant positive or negative effect on the cumulative abnormal returns (CARs) of the shares of listed companies.

\section{Keywords}

Global 100; Corporate social responsibility; Sustainability; Financial performance. 


\section{Introdução}

Após mudanças tecnológicas ocorridas no mundo decorrentes do processo de globalização, a sociedade observa uma tendência de desenvolvimento e crescimento em diversos países, de maneira que novos processos foram nela inseridos e, também, nas corporações. Percebe-se que esse processo de globalização tanto gerou benefícios e facilidades, a exemplo do desenvolvimento dos processos modernos de produção e melhorias nas condições trabalhistas, quanto problemas, como poluição, enchentes, aquecimento global, escassez de recursos, dentre outros.

Muitos desses problemas suscitaram cobrança por parte da sociedade no sentido de exigir mudanças de postura das empresas (Madorran \& Garcia, 2016), de maneira que estas pudessem se utilizar de processos produtivos que agredissem menos ao ambiente, além de realizarem programas e projetos que minimizassem os danos causados decorrentes deles (Silva, Coelho \& Cavalcante, 2016). Nesse contexto, surgiram as discussões associadas ao Desenvolvimento Sustentável (DS), o qual busca encontrar o equilíbrio entre diferentes aspectos, dentre eles, econômicos, sociais e ambientais.

De acordo com a Comissão Mundial Sobre o Meio Ambiente e Desenvolvimento - CMMAD, comissão responsável pela elaboração do Relatório de Brundtland (Our Common Future) em 1987, o DS é aquele que atende as necessidades das gerações presentes sem que comprometa os recursos necessários para o atendimento das necessidades das gerações futuras. O conceito de DS não implica em limites absolutos, mas em limitações impostas pela sociedade, dado o avanço tecnológico e seus impactos gerados na biosfera (Mitcham, 1995).

Nesse sentido, as corporações que, devido as suas atividades, produzirem maiores impactos no ambiente e na sociedade, poderão desenvolver suas atividades e se promoverem economicamente de maneira equitativa, visto que tais corporações têm condições de estabelecer mudanças perceptíveis na qualidade de vida da sociedade e minimizar danos ambientais gerados por suas atividades.

Atuar como uma corporação que busca, de alguma forma, propiciar melhorias para a sociedade, passou a ser considerado como importante meio para adquirir vantagem competitiva (Serpa \& Fourneau, 2007). Dessa forma, os investimentos realizados em atividades voltadas a Responsabilidade Social Corporativa (RSC) ou em organizações que desempenham tais atividades, são chamados Investimentos Socialmente Responsáveis (ISR). ISR são investimentos que incorporam valores éticos, proteção do ambiente, melhoria nas condições sociais e boa governança corporativa (Revelli \& Viviani, 2015).

Os ISRs, a exemplo de investimentos associados à energia limpa, tecnologia verde, agricultura sustentável, adequação às leis e normais ambientais, experimentam um período de expansão, passando do montante de U\$13,3 trilhões movimentados em 2012 para aproximadamente U\$21,4 trilhões no ano de 2014, apresentando um crescimento equivalente a 61\% (Aliança Global de Investimento Sustentável - GSIA, 2014). Para ilustrar este avanço, a proporção de ISR em relação ao total de ativos administrados profissionalmente na Europa passou de 49\% em 2012 para 58,8\%; nos Estados Unidos de 11,2\% em 2012 saltou para 17, 9\% em 2014; na Ásia, a proporção era de 0,6\% e em 2014 passou para 0,8\%. Em termos globais, a proporção em 2012 representava 21,5\%. E com o crescimento nos últimos anos, passou a representar 30,2\% em 2014.

Nessa direção, de acordo com Claro e Claro (2014, pp. 291-292), “as atividades de uma empresa em relação a questões ambientais e sociais podem influenciar tanto os interesses dos stakeholders como o próprio desempenho econômico-financeiro no longo prazo. Além disso, as informações de cunho social corporativo podem impactar nas decisões dos investidores e de empresas que ainda não praticam esse tipo de atividade. Partindo dessa questão e das mudanças de posturas adotadas por algumas instituições, algumas Bolsas de Valores (New York Stock Exchange NYSE, Bolsa de Mercadorias e Futuros Bovespa - BM\&FBovespa, Johannesburg Stock Exchange- JSE, London Stock Exchange- LSE) lançaram índices setoriais - social e de sustentabilidade - que envolvem um conjunto de empresas que indicam ter preocupação voltada para questões sociais e ambientais.

Além desses índices setoriais, empresas como a Corporate Knights e a Newsweek, elaboraram rankings mundiais, chamados de rankings verdes, ou rankings sustentáveis. Estes, têm a finalidade de reunir empresas que possuem os melhores desempenhos em sustentabilidade a nível mundial. Esses rankings, assim como os índices de mercado, são ferramentas que fornecem informações sobre o desempenho das empresas em ações voltadas à sustentabilidade e à RSC.

Acredita-se também que a divulgação desses rankings pode ser considerada uma informação importante para o mercado, por indicar quais empresas estão apresentando resultados relacionados às atividades de sustentabilidade, o que envolve aspectos econômicos, sociais e ambientais. Um exemplo desses rankings é o Global 100, uma classificação criada pela Corporate Knights no ano de 
2005 que reúne as 100 empresas consideradas mais sustentáveis do mundo de acordo com 12 critérios: energia, emissões de carbono, consumo de água, resíduos sólidos, capacidade de inovação, pagamentos de impostos, a relação entre o salário médio do trabalhador e o do CEO, planos de previdência corporativos, segurança do trabalho, percentual de mulheres na gestão e bônus por desempenho.

Nesse sentido, a divulgação do ranking pode servir de informação para investidores/acionistas que aplicam ou pretendem realizar investimentos em corporações que praticam atividades dessa natureza. Diante disto, a problemática desta pesquisa se pauta na seguinte questão: Qual o efeito causado nos retornos das ações das empresas após a divulgação de inclusão no ranking Global 100?

Dessa forma, o objetivo do artigo consistiu em analisar o efeito causado nos retornos das ações das empresas após a divulgação de inclusão no ranking Global 100 a partir da metodologia de estudo de eventos. O ranking é divulgado anualmente no Fórum Econômico Mundial que ocorre em Davos, na Suíça. O Global 100 evidencia o desempenho em sustentabilidade corporativa de 100 empresas a cada ano de lançamento; essas empresas podem ser de qualquer país, desde que atendam aos pré-requisitos estabelecidos para serem incluídas no ranking.

Todas as empresas com pelo menos o equivalente a US\$2 bilhões em capitalização de mercado compõem o universo de pesquisa considerado pela Corporate Knights. Essa informação é levantada todos os anos no dia $1^{\circ}$ de outubro. A partir deste levantamento inicial, as empresas selecionadas passam por mais 4 etapas para efeitos de "filtro", como: divulgação de sustentabilidade, F-score, categorias de produtos e sanções.

De acordo com a Corporate Knights, o Global 100 é o único ranking que utiliza uma abordagem metodológica orientada por dados para medir algo que eles chamam de "nebuloso", fazendo referência ao desempenho de sustentabilidade corporativa. Além disso, o Global 100 ganhou credibilidade no mundo dos negócios por empregar indicadores bem elaborados e definidos e também por utilizar um processo transparente. Assim, destacou-se em relação aos demais rankings existentes, que na maioria dos casos não explicam detalhadamente o processo de construção.

Diante destes aspectos, a presente pesquisa visa contribuir com uma evidência empírica a respeito do efeito causado pela informação referente à sustentabilidade corporativa nos retornos das ações das empresas listadas, usando para isso um ranking ainda pouco explorado na literatura, que busca reunir empresas com os melhores desempenhos em sustentabilidade corporativa.

Este artigo está estruturado da seguinte forma: a introdução, que apresenta o tema bem como problema e objetivo do estudo; uma revisão da literatura, que aborda a eficiência de mercado, e a relação entre investimentos socialmente responsáveis e o desempenho financeiro das corporações; os procedimentos metodológicos adotados; a exposição dos resultados e a discussão destes com a teoria. Por fim, apresentam-se as considerações finais e as referências utilizadas.

\section{Revisão da Literatura}

\subsection{Hipótese de Mercado Eficiente}

A eficiência de mercado é uma das áreas mais importantes da Teoria Financeira, tendo em vista que busca investigar o aspecto aleatório dos preços dos ativos, de modo que exista um mercado eficiente (em termos de expectativas de retornos) para todos os investidores que nele participam. O mercado eficiente é aquele em que os investidores podem escolher entre os papéis que representam a propriedade de atividades das empresas sob o pressuposto de que os preços de segurança, a qualquer momento, refletem totalmente a informação disponível (Fama, 1970).

Além disso, Fama estabeleceu três formas de testar a eficiência em um mercado de capitais: fraca, semiforte e forte (Marques, Ahlfeldt, Cruz, \& Silva, 2015). A forma fraca de eficiência diz respeito ao mercado em que as informações passadas dos títulos são disponíveis a todos os investidores de maneira igualitária (Dourado \& Tabak, 2014). A forma semiforte apresenta que o mercado absorve não apenas as informações passadas dos títulos, como também as informações públicas que estão disponíveis. E a forma de eficiência forte define que os preços dos títulos refletem as informações passadas, públicas e privadas.

Após a publicação do trabalho desenvolvido por Fama (1970), muitos pesquisadores desenvolveram estudos que testassem as formas de eficiência de mercado propostas pelo autor. E a partir de então, diversas críticas surgiram. As principais se referem às anomalias associadas ao calendário, o efeito janeiro (Geske \& Roll, 1983) e o efeito fim de semana (French, 1980). Além das anomalias associadas ao calendário, existem anomalias chamadas de fundamentais ou de valor, como o efeito de Sobre-Reação, no qual os investidores dão maior importância a dados recentes do 
que a dados passados, provocando movimentos extremos nos preços; o efeito tamanho, no qual os retornos de firmas pequenas tendem a serem maiores do que os retornos de firmas grandes; efeito preço/lucro, onde os retornos de empresas com baixo índice P/L são superiores aos das empresas com alto índice P/L (Camargos \& Barbosa, 2003b).

Diante deste contexto de críticas, Fama (1991) reconheceu as fragilidades na HME apresentada em 1970 e fez uma reclassificação para formas de eficiência fraca, semiforte e forte, respectivamente: testes para previsibilidade de retornos, estudo de eventos e testes para informações privadas. Os testes para previsibilidade de retornos consideram a previsibilidade transversal de retornos, ou seja, testes de modelos de precificação de ativos e as anomalias (como o efeito do tamanho) e os efeitos sazonais nos retornos (Camargos \& Barbosa, 2003b; Galdão \& Famá, 1998; Marques et al., 2015; Mussa, Yang, Trovão \& Famá, 2008).

O teste chamado de estudo de eventos substituiu a forma semiforte de eficiência. Esse teste é utilizado para identificar quão rápido as informações disponíveis (passadas e públicas) são refletidas nos preços dos ativos. A informação divulgada, neste caso, é considerada como evento, no qual o mercado o precifica instantaneamente (caso ele seja eficiente), uma vez que este seja considerado relevante (Belo \& Brasil, 2006; Camargos \& Barbosa, 2003b; Forti, Peixoto, \& Santiago, 2009; Marques et al., 2015). A forma forte de eficiência foi substituída por testes para informações privadas. O principal foco desse tipo de teste é a verificar a eficiência de mercado utilizando como objeto os fundos de pensão bem como seus gestores, buscando identificar o uso de informação privada através da medição de retornos anormais durante longos períodos (Camargos \& Barbosa, 2003b; Fama, 1991).

O ambiente institucional é de extrema relevância para o bom funcionamento das organizações. Nesse sentido, a eficiência de mercado depende desse ambiente e de como a disponibilidade e obtenção de informações funcionam (DiMaggio \& Powell, 2005). Muitas evidências existem para comprovar a teoria proposta por Fama (1970), assim como existem outras para refutá-la.

Percebe-se nesse sentido, que informação é um elemento essencial para o funcionamento dos mercados, uma vez que se espera que a maior quantidade de investidores possa ter acesso e tomar suas decisões de maneira racional. Nessa direção, a informação, além de ser primordial no apreçamento dos ativos, é considerada necessária para a boa alocação de recursos. Informações referentes à sustentabilidade corporativa e a prática da RSC por meio do ISR têm sido constantemente consideradas no mercado financeiro, visto que esse tipo de atividade vem aumentando nos últimos anos.

\subsection{Evidências Empíricas}

De acordo com o USSIF (United States Social Investment Forum) (2002), ISRs compreendem um extenso e crescente portfólio de produtos e investimentos, desde ações e títulos, até capital de risco. Os ISRs refletem uma preocupação dos investidores com questões sociais (Bolsa de Valores, Mercadorias e Futuros - BM\&FBovespa, 2016). Esses investimentos utilizam critérios sociais, ambientais, éticos e/ou de governança na seleção ou gerenciamento dos portfólios. O ISR é orientado para o investidor e a RSC é orientada para a empresa (Soppe, 2009).

Existem diversos estudos encontrados na literatura que investigaram a relação entre desempenho financeiro e a prática da responsabilidade social corporativa (Anderson-Weir, 2010; Cheung, 2011; Curran \& Moran, 2007; Lyon \& Shimshack, 2015; Madorran \& Garcia, 2016; Murguia \& Lence, 2015; Mutezo, 2014; Oberndorfer, Schmidt, Wagner, \& Ziegler, 2013; Schaeffer, Borba, Rathmann, Szklo, \& Branco, 2012; Wang \& Chen, 2015). Dentre eles, encontram-se relações positivas, negativas e neutras, de modo que não se estabeleceu um consenso sobre o impacto de ISR ou da RSC no desempenho econômico financeiro das corporações.

Em relação aos achados associados à relação neutra, têm-se as pesquisas conduzidas por Curran e Moran (2007) e Cheung (2011). Curran e Moran (2007) analisaram se o desempenho financeiro é afetado por anúncios positivos ou negativos. Para isso, os autores utilizaram a inclusão e a exclusão de empresas do Reino Unido no FTSE4Good Index. Os resultados não foram estatisticamente significativos, embora o anúncio positivo tenha gerado movimentos positivos nos preços das ações e os anúncios negativos geraram movimentos negativos. Cheung (2009) investigou o impacto de inclusões e exclusões de empresas no DJSI no período de 2002 a 2008, sendo o impacto mensurado em termos de retorno, risco e liquidez. Os resultados não confirmaram a hipótese de que o anúncio do evento tem um significativo impacto sobre os retornos das ações, seja ela a inclusão no índice ou exclusão.

No que se refere aos achados associados às relações positivas e negativas, Anderson-Weir (2010) investigou os efeitos da publicação do Green Ranking publicado pela Newsweek em 2009 
sobre o desempenho financeiro das empresas presentes na lista. O autor constatou que os investidores reagem negativamente à notícia de que uma empresa pretende ser mais ecológica. Já Schaeffer et al. (2012), analisaram o efeito causado no valor de mercado das empresas de petróleo que aderiram ao DJSI World e analisaram a volatilidade das séries de preços dessas empresas. Os resultados apresentaram que apenas duas empresas tiveram um declínio em seus betas, mostrando diminuição no risco dessas empresas, mas sem qualquer alteração na volatilidade ou associação com o preço do petróleo em função da inclusão no DJSI.

Foi também analisado o impacto da inclusão de empresas alemãs em dois índices de ações de sustentabilidade, o Dow Jones STOXX e o DJS/ World por Oberndorfer et al. (2013). Os autores identificaram que enquanto os retornos anormais cumulativos médios foram não significativos para o caso de uma empresa ter sido incluída no D/SI STOXX, a inclusão no D/SI Global conduziu a impactos negativos fortes, revelando que o mercado de ações alemão "penalizou" a inclusão de empresas em índices de sustentabilidade de maior visibilidade, pois o DJSI Global tem ações de empresas de diversas Bolsas de Valores do mundo.

Wang \& Chen (2015) investigaram como o mercado americano reagiu à informação de inclusão e exclusão de empresas no índice Dow jones de sustentabilidade. Além disso, os mesmos autores investigaram como investidores dos Estados Unidos e Taiwan reagiram a informações divulgadas, referentes a nomeações, inclusões e prêmios relacionados ao desempenho de RSC. Os principais resultados sugerem que os investidores americanos não apresentaram um reconhecimento significativo pelo fato das empresas estarem incluídas em um índice de sustentabilidade. Já os resultados referentes a Taiwan demonstraram que os prêmios recebidos por empresas de médio porte apresentam resultados positivos e significativos, indicando uma predisposição dos investidores a aplicar recursos em empresas que realizam atividades de sustentabilidade e RSC.

Lyon \& Shimshack (2015) desenvolveram uma pesquisa na qual foi estudado o impacto causado nos retornos do mercado após a divulgação realizada pela Newsweek em 2009 de um ranking com as 500 maiores empresas americanas com bons desempenhos em sustentabilidade. Os principais achados apontaram que as 100 empresas melhores classificadas no ranking obtiveram retornos anormais após a divulgação de informações que foram mais elevados do que as empresas classificadas na parte inferior do ranking.

Murguia \& Lence (2015) investigaram como o mercado de ações reagiu em relação à divulgação do G100 elaborado pela revista Newsweek em 2010. O ranking G100 é composto por 100 empresas com melhores desempenhos em sustentabilidade. Como a análise foi realizada individualmente e coletivamente (em forma de carteira), os resultados obtidos pelos autores indicaram que os investidores reagiram à divulgação do ranking alterando positivamente os preços das ações das empresas, mas não alterou o valor da carteira.

\subsection{Hipótese da Pesquisa}

Dentre as diferentes abordagens que consideram aspectos associados à responsabilidade social e sustentabilidade no contexto empresarial, duas se destacam, a saber: clássica e contemporânea. Segundo Arantes (2006), a visão clássica defende o fato de que a única responsabilidade da empresa é a de geração de lucro e empregos, indo ao encontro do pensamento defendido por Friedman (1970). A visão contemporânea, por outro lado, pondera que as empresas devem utilizar no seu modelo de gestão ações complacentes com seus stakeholders, com os quais deve manter transparência e ética (Arantes, 2006; Oliveira, Almeida, Rocha, Tortato, \& Silva, 2015).

As condições econômicas afetam o grau de envolvimento social das organizações e essa relação é afetada por um conjunto de fatores institucionais (Campbell, 2007). Esses fatores podem ser citados como desempenho financeiro, concorrência, regulação, envolvimento em ONG's e impressa (mídia) no ambiente de atuação empresarial, associações de empregadores e envolvimento com sindicatos, grupos comunitários, investidores e outras partes interessadas.

Alguns desses fatores podem ser chamados de stakeholders, dos quais são indivíduos que têm relação com a organização, como clientes, fornecedores, funcionários, gerentes, governo, comunidade e o próprio meio no qual a empresa se situa (Donaldson \& Preston, 1995). Dessa forma, percebe-se uma aproximação da teoria dos stakeholders com a sustentabilidade corporativa, uma vez que organizações que desempenham atividades, programas e projetos sociais e ambientais levam em consideração a responsabilidade social da mesma.

Diante do exposto, a teoria dos stakeholders norteia as questões relacionadas a existência de uma relação positiva entre sustentabilidade corporativa/responsabilidade social corporativa e o desempenho financeiro das organizações. Essa teoria possui a premissa básica de que as 
organizações que têm preocupação social e ambiental e as desenvolvem, têm um resultado financeiro superior as que não o fazem. Partindo dessa premissa e considerando algumas evidências empíricas Wang \& Chen (2015), Lyon \& Shimshack (2015) e Murgia \& Lence (2015), a hipótese lançada neste estudo é a seguinte: há um efeito positivo nos retornos das ações das empresas após a divulgação de inclusão no ranking Global 100.

Deve-se levar em consideração que a hipótese desta pesquisa, norteada pela teoria dos stakeholders, tem o argumento de que estar no ranking Global 100, demonstra que a empresa realiza atividade sustentável e, neste caso, o mercado financeiro considera esse engajamento como sendo um aspecto positivo. Neste caso, a hipótese sugere haver possibilidade de retornos anormais, trazendo maior rentabilidade em relação ao comportamento do mercado. Já no que diz respeito à hipótese nula, $H_{0}$, seria: não há efeito positivo nos retornos das ações das empresas após a divulgação de inclusão no ranking Global 100. Nessa direção, $H_{0}$ se refere a eficiência de mercado semiforte de Fama (1991).

\section{Procedimentos Metodológicos}

A presente pesquisa é considerada de natureza quantitativa, descritiva e explicativa. A pesquisa quantitativa considera o que pode ser quantificável, para posterior tratamento e análise. A pesquisa descritiva se utiliza de técnicas para coletas de dados que seguem um padrão (Kauark, Manhães, \& Medeiro, 2010; Martins Júnior, 2011). Além disso, visa descobrir e observar fenômenos existentes ou estabelecer relações entre diversas variáveis, a fim de descrever, classificar, comparar, avaliar e analisar estas relações e fenômenos. Já a pesquisa explicativa, segundo Gil (2007), identifica fatores que contribuem com a ocorrência de fenômenos. É extremamente associada a pesquisa descritiva, uma vez que é necessário descrever os fatores relacionados ao fenômeno observado.

\subsection{Estudo de Eventos}

O Estudo de Eventos é uma metodologia que possibilita o teste da eficiência de mercado em sua forma semiforte, uma vez que tem por objetivo mensurar o efeito de uma informação divulgada nos preços das ações das empresas. Esses estudos buscam refletir como o mercado, analistas e investidores reagem a boas notícias e más notícias sobre empresas específicas (Curran \& Moran, 2007). O procedimento de operacionalização do método Estudo de Eventos tem algumas etapas, listadas a seguir:

Etapa 1 - Definição do evento: Para fins desta pesquisa, o evento considerado foi o dia da divulgação do ranking Global 100, sendo levada em consideração apenas a data de entrada de determinada empresa no ranking. A Tabela 1 traz a quantidade de empresas que foram classificadas no ranking no período de 2005 a 2016 e as respectivas datas de divulgação.

Conforme pode ser observado na Tabela 1, além das datas de divulgação dos rankings ao longo dos anos, encontra-se a quantidade de empresas presentes nas listas (362), a quantidade que empresas que não dispõem de dados para investigação (64), a amostra final (298), a quantidade de empresas que saíram ao longo dos anos (302), as que reentraram (259), bem como as que permaneceram no ranking a cada ano.

O evento do ano de 2011 (29/01/2011) aconteceu em um fim de semana e, para esses casos, utiliza-se a cotação do dia útil seguinte, neste caso, dia 31/01/2011, conforme proposto por Wang e Chen (2015). A análise foi feita em torno dos dias que a informação foi divulgada, pois o período anterior à data do evento (considerada data "0") visa à identificação do uso de informação privilegiada (Camargos \& Barbosa, 2003a). Por outro lado, o período posterior à data "0" visa identificar a velocidade na qual os preços se ajustam à nova informação.

A escolha da janela do evento tem caráter subjetivo e depende de cada pesquisador. Nesta pesquisa foram analisados o dia do evento, data " 0 " e as janelas de 3 dias $(-1,0,1) ; 5$ dias $(-2,0,2) ; 7$ dias $(-3 ; 0 ; 3) ; 9$ dias $(-4,0,4), 11$ dias $(-5,0,5), 13$ dias $(-6,0,6), 15$ dias $(-7,0,7), 17$ dias $(-8,0,8), 19$ dias $(-9,0,9)$ e 21 dias $(-10,0,10)$, sendo os valores negativos os dias antes do evento, o dia zero "0" como a data do evento e os números positivos os dias posteriores ao evento. 
Tabela 1

Data do evento e quantidade de empresas

\begin{tabular}{|c|c|c|c|c|c|c|c|c|}
\hline Ano & $\begin{array}{l}\text { Data de } \\
\text { Divulgação }\end{array}$ & $\begin{array}{c}\text { Qtd. de } \\
\text { empresas (Novas } \\
\text { entradas) }\end{array}$ & $\begin{array}{l}\text { Sem } \\
\text { dados }\end{array}$ & $\begin{array}{c}\text { Amostra } \\
\text { final }\end{array}$ & Saídas & Reentradas & $\begin{array}{l}\text { Empresas que } \\
\text { permaneceram }\end{array}$ & $\begin{array}{l}\text { Total de } \\
\text { empresas/ } \\
\text { ano }\end{array}$ \\
\hline 2005 & $28 / 01 / 2005$ & 100 & 19 & 81 & - & - & & 100 \\
\hline 2006 & $27 / 01 / 2006$ & 28 & 7 & 21 & 27 & _ & 72 & 100 \\
\hline 2007 & $24 / 01 / 2007$ & 31 & 8 & 23 & 33 & 4 & 65 & 100 \\
\hline 2008 & $23 / 01 / 2008$ & 26 & 8 & 18 & 28 & 8 & 66 & 100 \\
\hline 2009 & $28 / 01 / 2009$ & 27 & 5 & 22 & 29 & 11 & 62 & 100 \\
\hline 2010 & $27 / 01 / 2010$ & 28 & 5 & 23 & 44 & 26 & 46 & 100 \\
\hline 2011 & $29 / 01 / 2011$ & 22 & 5 & 17 & 23 & 29 & 49 & 100 \\
\hline 2012 & $24 / 01 / 2012$ & 19 & 1 & 18 & 17 & 29 & 52 & 100 \\
\hline 2013 & $23 / 01 / 2013$ & 39 & 5 & 34 & 38 & 27 & 33 & $99 *$ \\
\hline 2014 & $22 / 01 / 2014$ & 14 & 1 & 13 & 26 & 39 & 47 & 100 \\
\hline 2015 & $21 / 01 / 2015$ & 17 & 0 & 17 & 19 & 41 & 42 & 100 \\
\hline 2016 & $21 / 01 / 2016$ & 11 & 0 & 11 & 18 & 44 & 45 & 100 \\
\hline & Total & 362 & 64 & 298 & 302 & 259 & & \\
\hline
\end{tabular}

Nota. Fonte: Elaboração Própria, 2017.

* O ano de 2013 só teve 99 empresas listadas no ranking.

Etapa 2 - Critérios de seleção: Foram selecionadas as empresas incluídas nos rankings Global 100 ao longo dos 12 anos de publicação (2005-2016). Apesar de algumas empresas terem participado de vários rankings, a presente pesquisa considerou apenas o primeiro ingresso como evento para análise. Nessa direção, a amostra inicial desta pesquisa após a verificação de disponibilidade de dados foi composta por 308 ações de empresas distribuídas em 25 países.

As variáveis utilizadas foram as cotações das ações e dos índices de mercado. Considerando aqui o índice da Bolsa de Valores, no qual a empresa é prioritariamente listada (ação cotada na bolsa do respectivo país da empresa). A coleta de dados foi realizada no dia 10 de junho de 2016 no banco de dados da Thomson Reuters ${ }^{\circledR}$, todos convertidos para Dólar (US\$), seguindo o procedimento utilizado por Murguia \& Lence (2015).

Procedimentos para obtenção dos retornos normais e anormais: Nesta etapa, verificou-se o impacto do evento no preço das ações através da medida de retorno anormal. O retorno anormal, neste caso, é a diferença entre o retorno observado e o retorno esperado, dado pela equação:

$$
A R_{i t}=R_{i t}-E\left(R_{i t} \mid X_{t}\right)
$$

Na qual $A R_{i t}$ é o retorno anormal da empresa $i$ na data $t ; R_{i t}$ é o retorno observado e $E\left(R_{i t} \mid X_{t}\right)$ é o retorno esperado do ativo i na data $t$ com base nas informações $X_{t}$.

Para realizar o cálculo do retorno normal, no que se refere ao componente $R_{i t}$, ou seja, o retorno observado pode-se optar pela forma discreta ou contínua (Brooks, 2008; Camargos \& Barbosa, 2003a; Soares, Rostagno, \& Soares, 2002). Aqui, foi utilizado o cálculo pelo regime de capitalização contínua que é realizado a partir da fórmula:

$$
r=\ln \left(\frac{P_{t}}{P_{t-1}}\right)
$$

No qual $r$ é o retorno observado e $\ln \left(\frac{P_{t}}{P_{t-1}}\right)$ é o logaritmo da divisão entre o preço do título no período $t$ e o preço do título no período $t-1$. 
Etapa 3 - Procedimento de estimação: O procedimento de estimação é realizado para a obtenção do retorno esperado $E\left(R_{i t}\right)$, que é aquele que seria obtido caso o evento não ocorresse. Utilizou-se uma quantidade de dias anteriores à janela do evento. Esses dias são chamados de janela de estimação e são utilizados os dias anteriores à janela do evento para que os parâmetros do modelo não sejam tendenciosos, no sentido de capturar algum possível efeito do evento. A escolha da janela de estimação é também feita de forma arbitrária pelo pesquisador, mas que não deve ser inferior a 120 dias (Campbell, MacKinlay, \& Lo, 1997). Nesta pesquisa foram utilizados 160 dias como janela de estimação, o equivalente a 160 pregões.

Existem três formas de realizar o cálculo do retorno esperado: por meio do retorno ajustado à média, do retorno ajustado ao mercado e do modelo de mercado (Brown \& Warner, 1985). Nesta pesquisa foi utilizado o modelo de mercado que relaciona linearmente o retorno de um determinado ativo financeiro com o retorno da carteira de mercado (que foi representado pelo índice de mercado da Bolsa de Valores que a empresa é prioritariamente listada). Assim, o retorno esperado foi calculado a partir do modelo de mercado, que é dado pela equação:

$$
R_{i t}=\alpha_{i}+\beta_{i} R_{m t}+\varepsilon_{i t}
$$

Na qual $R_{i t}$ é o retorno do ativo $i$ na data $t ; \alpha_{i}$ é o intercepto da reta de regressão para o ativo i e $\beta_{i}$ é o coeficiente angular; $R_{m}$ é o retorno do mercado na data $t ; \varepsilon_{i t}$ é o resíduo da regressão do ativo i na data $t$, que segue uma distribuição normal com média zero e variância $\sigma^{2}$.

Nesta pesquisa foi utilizado o modelo de mercado para estimação do retorno esperado. Como esse modelo relaciona linearmente o retorno do ativo com a carteira de mercado, foram utilizados os índices de mercado das respectivas bolsas de valores do país em que as ações das empresas são negociadas como proxies para o retorno do mercado. A estimação é feita para cada ação de cada empresa.

O modelo foi estimado através do método de Mínimos Quadrados Ordinários - MQO, pois é um estimador que traz resultados consistentes em relação à aplicação de estudo de eventos (Brown \& Warner, 1985; MacKinlay, 1997; Jonsson \& Radeschnig, 2014; Murguia \& Lence, 2015). Também foi utilizado o modelo de heterocedasticidade condicional, Generalized Autoregressive Conditional Heteroscedasticity - GARCH para o caso de identificação de efeitos ARCH nos resíduos das regressões estimadas. Todas as estimações e cálculos foram realizados com a utilização dos softwares $R \AA$ e Eviews $\AA$.

Para o caso do MQO foi levado em consideração a estatística F e os parâmetros, de modo que estes precisaram ser significativos para determinada regressão ser incluída na análise. Os pressupostos do modelo também devem ser atendidos, sejam eles: normalidade, homocedasticidade e autocorrelação (Brooks, 2008). Para o caso do pressuposto da normalidade, utilizaram-se os testes Jarque-Bera e Shapiro e Francia; no caso da homocedasticidade, foram utilizados os testes de White e Breusch-Pagan; e em relação à detecção da autocorrelação residual, foram utilizados os testes de Durbin-Watson e Breusch-Godfrey. Utilizou-se também o teste ARCH LM desenvolvido por Engle (1982), para detectar ou não a presença de efeitos ARCH.

Etapa 4 - Procedimentos de Teste: após o cálculo dos retornos normais - observado e esperado - obtém-se o retorno anormal de cada ação através da equação:

$$
A R_{i t}=R_{i t}-\left(\hat{\alpha}_{i}+\hat{\beta}_{i} R_{m t}\right)
$$

Na qual $A R_{i t}$ é o retorno anormal do ativo $i$ no dia $t, R_{i t}$ é o retorno observado, $\hat{\alpha}_{i} e \hat{\beta}_{i}$ são os parâmetros da regressão estimada e $R_{m t}$ é o retorno do índice de mercado na data $t$.

Uma vez que a janela de evento é composta de vários dias, faz-se necessária uma agregação dos retornos ao longo das janelas definidas, até a janela máxima de 21 dias, para assim se obter uma única medida de retorno anormal. Dessa forma, os retornos anormais são acumulados, através da técnica Cumulative Abnormal Return - CAR, dada pela fórmula: 


$$
C A R_{i}\left(t_{1}, t_{2}\right)=\sum_{t=t_{1}}^{t_{2}} A R_{i t} \quad \text { Acumulação no tempo }
$$

Após a obtenção dos retornos anormais e retornos anormais acumulados, foram realizados testes para identificar a significância desses retornos e assim responder ao objetivo da pesquisa, que é analisar o efeito causado nos retornos das ações das empresas após a divulgação de inclusão no ranking Global 100. Como teste paramétrico, foi utilizado o Teste $t$ e como testes não paramétricos o teste de Sinais Simples e o teste de Sinais de Wilcoxon.

Etapa 5 - Resultados empíricos: Nesta etapa serão descritos os resultados empíricos auferidos nos testes.

\section{Análise e Discussão dos Resultados}

\subsection{Análises das Regressões Estimadas}

Em relação aos procedimentos de estimação, utilizou-se o modelo de mercado para as 308 ações da amostra. As regressões consideradas foram aquelas que apresentaram $\mathrm{F}$ estatístico e beta significativos. Em seguida, testaram-se os pressupostos de normalidade, autocorrelação e homocedasticidade. Para as regressões que apresentaram efeitos $\mathrm{ARCH}$, foram estimadas novamente usando um modelo GARCH de ordem $(1,1)$.

Das 308 regressões estimadas, 42 foram excluídas por não apresentarem parâmetros e estatística F significativos. Dessa forma, a amostra final se constituiu de 266 ações/regressões. O pressuposto da normalidade foi violado em 151 regressões. Entretanto, esse pressuposto foi relaxado, pois segundo o Teorema do Limite Central, a média de uma amostra (suficientemente grande) converge para uma distribuição normal (Brooks, 2008; Hansen, 2016). A Tabela 2 traz o resumo destes resultados iniciais.

Tabela 2

Resumo das quantidades de ações - significância e pressupostos

\begin{tabular}{lr} 
Ações & 308 \\
\hline Não significativas & 36 \\
Não significativas com presença de ARCH & 7 \\
Total de regressões com presença de ARCH & 23 \\
Significativas estimadas por GARCH & 10 \\
Regressões que aceitaram todos os pressupostos MQO & 40 \\
Problema de normalidade residual & 151 \\
Problema de heterocedasticidade & 25 \\
Autocorrelação residual & 40 \\
Excluídas da amostra - MQO & $(29)$ \\
Excluídas da amostra - GARCH & $(13)$ \\
\hline
\end{tabular}

Total final de ações da amostra $\quad 266$

Nota. Fonte: Elaboração Própria, 2017.

Em relação à homoscedasticidade, 25 regressões rejeitaram a hipótese nula de homoscedasticidade dos testes. Para estes casos, as regressões foram estimadas novamente com um modelo de heterocedasticidade corrigida pelo método de Mínimos Quadrados Ponderados (MQP). No caso do pressuposto de autocorrelação residual, 40 regressões apresentaram esse problema e foram corrigidas através do teste de Cochrane-Orcutt, que estima a regressão corrigindo o problema da autocorrelação. No que diz respeito ao modelo $\operatorname{GARCH}(1,1), 10$ regressões foram estimadas considerando a variância condicional. 


\subsection{Estatísticas Descritivas e Análises dos Retornos Anormais Acumulados - CARS}

As estatísticas descritivas dos retornos anormais e dos retornos anormais acumulados apresentam de maneira geral, o comportamento dos retornos das ações que compõe a amostra. A Tabela 3 apresenta os resultados das medidas:

Tabela 3

Estatística descritiva dos ARS e dos CARs

\begin{tabular}{lcccc}
\hline Medidas & AR & AR Médio & CAR & CAR Médio \\
\hline Média & 0,0188 & 0,0001 & 0,3850 & 0,0014 \\
Mediana & $-0,0067$ & 0,0000 & 0,4161 & 0,0016 \\
Mínimo & $-0,5713$ & $-0,0021$ & $-0,1941$ & $-0,0007$ \\
Máximo & 0,8101 & 0,0030 & 1,0198 & 0,0038 \\
Assimetria & 0,2958 & 0,2962 & $-0,0887$ & $-0,1409$ \\
Curtose & $-1,0579$ & $-1,0579$ & 0,2214 & 0,2214 \\
Desvio padrão & 0,4216 & 0,0016 & 0,3489 & 0,0013 \\
Variância & 0,1778 & 0,0000 & 0,1217 & 0,0000 \\
\hline
\end{tabular}

Nota. Fonte: Dados da Pesquisa, 2017.

De acordo com os resultados apresentados na Tabela 3, o retorno anormal e o retorno anormal acumulado das ações da amostra em toda a janela de evento composta por 21 dias foram 0,0188 e 0,3850 , respectivamente. A média dos retornos anormais médios e anormais acumulados médios é próxima de zero, sendo 0,0001 a média do retorno anormal médio e 0,0014 a média do retorno anormal acumulado médio. Esse resultado indica um retorno positivo, porém próximo de zero, demonstrando pouca discrepância em relação ao retorno normal (retorno igual a zero). Já o retorno anormal em relação à mediana calculada é negativo para o retorno anormal e positivo para o retorno anormal acumulado, ambas as medidas próximas de zero, sendo -0,0067 e 0,4161, respectivamente. O AR mínimo observado é de -0,5713 e máximo de 0,8101 e o AR médio mínimo observado é de $-0,0021$ e máximo de 0,0030. Em relação ao CAR, o valor mínimo foi de -0,1941 e máximo de 1,0198 e o CAR médio mínimo observado -0,0007 e máximo 0,0038.

Em relação ao formato os ARs têm distribuição assimétrica positiva com curtose platicúrtica. Já os retornos anormais acumulados têm distribuição assimétrica negativa com curtose leptocúrtica. Os seja, as distribuições dos ARs e CARs são diferentes e não normais, resultados também encontrados após a realização dos testes de normalidade de cada ação individual.

No que se refere às medidas de dispersão, o desvio padrão é do AR e AR médio é de 0,4216 ; 0,0016 e variância de 0,1777; 0,000 respectivamente. O CAR e o CAR médio têm desvio padrão 0,$3489 ; 0,0013$ e variância de 0,1217; 0,000, respectivamente. Nota-se que a dispersão dos dados em relação à média é maior nos ARs do que nos CARs, ou seja, os dados referentes aos ARs têm maior variabilidade do que os dados dos CARs.

Neste caso, apenas a análise descritiva dos dados não permite fazer afirmações em relação ao possível efeito do evento, possibilitando retornos anormais significativos, ou a respeito da eficiência de mercado, em que a informação já estaria refletida nos preços das ações analisadas. Para tanto, recorreu-se a testes de hipóteses paramétricos e não paramétricos, a fim de identificar se CARs são estatisticamente diferentes de zero e, consequentemente, se o evento impactou os preços das ações.

Os testes de significância dos retornos anormais acumulados foram realizados para cada data do evento (ano), por setor da indústria e de forma geral, com todos os eventos juntos. Com a análise por data de evento buscou-se identificar se o anúncio do ranking impactou o preço das ações das empresas que entraram a cada ano, de maneira que fosse possível analisar ano a ano, tendo em vista que o evento considerado é a inclusão de determinada empresa no ranking.

Os testes utilizados estão apresentados nas Tabelas 4 e 5 , sendo uma com o teste $t$ paramétrico e outra com os testes de sinais não paramétricos. Em ambos os testes, a hipótese nula é de que o evento não causou efeito nos retornos das ações das empresas e, nesse sentido, os CARs são estatisticamente iguais à zero. O teste t pressupõe que a distribuição dos dados utilizados seja próxima de uma distribuição normal, principalmente para pequenas amostras. Para analisar a distribuição dos CARs aplicou-se o teste Jarque-Bera e o teste de Shapiro-Francia. Os espaços nas tabelas com um traço (-) correspondem aos casos em que os dados não se distribuem normalmente. 
O efeito da informação de sustentabilidade corporativa nos retornos das ações: análise de empresas incluídas no ranking Global 100

Tabela 4

Teste Paramétrico: $\mathrm{t}$

\begin{tabular}{|c|c|c|c|c|c|c|c|c|c|c|c|c|}
\hline Janela & 2005 & 2006 & 2007 & 2008 & 2009 & 2010 & 2011 & 2012 & 2013 & 2014 & 2015 & 2016 \\
\hline 0 & $\begin{array}{l}1,238 \\
(0,22)\end{array}$ & - & - & $\begin{array}{l}0,541 \\
(0,59)\end{array}$ & - & $\begin{array}{c}- \\
2,282 \\
(0,03)\end{array}$ & $\begin{array}{c}- \\
0,976 \\
(0,34) \\
\end{array}$ & $\begin{array}{l}0,618 \\
(0,54)\end{array}$ & $\begin{array}{l}2,187 \\
(0,03)\end{array}$ & $\begin{array}{r}-0,755 \\
(0,46)\end{array}$ & $\begin{array}{c}- \\
0,048 \\
(0,96)\end{array}$ & $\begin{array}{l}1,609 \\
(0,14)\end{array}$ \\
\hline$(-1,01)$ & $\begin{array}{r}-0,874 \\
(0,38)\end{array}$ & $\begin{array}{c}- \\
1,639 \\
(0,12)\end{array}$ & $\begin{array}{c}- \\
1,036 \\
(0,31)\end{array}$ & $\begin{array}{c}- \\
0,299 \\
(0,77) \\
\end{array}$ & $\begin{array}{l}0,598 \\
(0,56)\end{array}$ & $\begin{array}{l}-2,051 \\
(0,05)\end{array}$ & $\begin{array}{l}0,966 \\
(0,35) \\
\end{array}$ & $\begin{array}{l}0,960 \\
(0,35)\end{array}$ & $\begin{array}{l}2,961 \\
(0,00)\end{array}$ & $\begin{array}{c}-0,353 \\
(0,73)\end{array}$ & $\begin{array}{l}0,158 \\
(0,88) \\
\end{array}$ & $\begin{array}{l}0,854 \\
(0,42)\end{array}$ \\
\hline$(-2,0,2)$ & $\begin{array}{l}0,513 \\
(0,61)\end{array}$ & $\begin{array}{c}- \\
0,581 \\
(0,57) \\
\end{array}$ & $\begin{array}{c}- \\
0,253 \\
(0,80) \\
\end{array}$ & $\begin{array}{c}0,662 \\
(0,52)\end{array}$ & $\begin{array}{c}- \\
0,297 \\
(0,77)\end{array}$ & $\begin{array}{r}-1,855 \\
(0,08)\end{array}$ & $\begin{array}{c}- \\
0,702 \\
(0,49)\end{array}$ & $\begin{array}{c}- \\
0,026 \\
(0,98)\end{array}$ & $\begin{array}{l}1,060 \\
(0,30)\end{array}$ & $\begin{array}{r}-0,330 \\
(0,74)\end{array}$ & $\begin{array}{c}- \\
0,311 \\
(0,76)\end{array}$ & - \\
\hline$(-3,0,3)$ & $\begin{array}{l}0,086 \\
(0,93)\end{array}$ & $\begin{array}{l}0,493 \\
(0,63) \\
\end{array}$ & $\begin{array}{l}0,494 \\
(0,62)\end{array}$ & $\begin{array}{l}0,861 \\
(0,40)\end{array}$ & $\begin{array}{c}- \\
0,572 \\
(0,57) \\
\end{array}$ & $\begin{array}{c}-1,268 \\
(0,22)\end{array}$ & $\begin{array}{l}0,532 \\
(0,60) \\
\end{array}$ & $\begin{array}{l}0,625 \\
(0,54)\end{array}$ & $\begin{array}{l}1,624 \\
(0,11)\end{array}$ & $\begin{array}{r}-1,928 \\
(0,07)\end{array}$ & $\begin{array}{l}0,165 \\
(0,87) \\
\end{array}$ & - \\
\hline$(-4,0,4)$ & $\begin{array}{r}-1,034 \\
(0,30)\end{array}$ & $\begin{array}{l}0,726 \\
(0,48)\end{array}$ & $\begin{array}{l}0,794 \\
(0,43)\end{array}$ & $\begin{array}{l}1,129 \\
(0,27)\end{array}$ & $\begin{array}{c}- \\
0,939 \\
(0,36)\end{array}$ & $\begin{array}{c}-0,671 \\
(0,51)\end{array}$ & $\begin{array}{l}0,138 \\
(0,89)\end{array}$ & $\begin{array}{l}0,416 \\
(0,68)\end{array}$ & $\begin{array}{l}1,478 \\
(0,15)\end{array}$ & $\begin{array}{c}2,342 \\
(0,03)\end{array}$ & $\begin{array}{l}0,785 \\
(0,44)\end{array}$ & - \\
\hline$(-5,0,5)$ & $\begin{array}{c}-1,526 \\
(0,13)\end{array}$ & $\begin{array}{l}0,589 \\
(0,56)\end{array}$ & $\begin{array}{l}1,268 \\
(0,22)\end{array}$ & $\begin{array}{l}0,561 \\
(0,58)\end{array}$ & $\begin{array}{c}0,692 \\
(0,50)\end{array}$ & $\begin{array}{r}-0,551 \\
(0,59)\end{array}$ & $\begin{array}{l}0,346 \\
(0,73)\end{array}$ & $\begin{array}{l}0,893 \\
(0,38)\end{array}$ & $\begin{array}{l}0,677 \\
(0,50)\end{array}$ & $\begin{array}{c}- \\
3,104 \\
(0,00)\end{array}$ & $\begin{array}{l}0,224 \\
(0,82)\end{array}$ & - \\
\hline$(-6,0,6)$ & $\begin{array}{c}- \\
2,024 \\
(0,04)\end{array}$ & $\begin{array}{c}- \\
0,508 \\
(0,62)\end{array}$ & $\begin{array}{l}0,773 \\
(0,45)\end{array}$ & $\begin{array}{l}0,164 \\
(0,87)\end{array}$ & $\begin{array}{c}- \\
0,646 \\
(0,53)\end{array}$ & $\begin{array}{r}-1,314 \\
(0,20)\end{array}$ & $\begin{array}{c}- \\
0,165 \\
(0,87)\end{array}$ & $\begin{array}{l}1,334 \\
(0,20)\end{array}$ & $\begin{array}{l}1,372 \\
(0,18)\end{array}$ & $\begin{array}{c}- \\
3,255 \\
(0,00)\end{array}$ & $\begin{array}{l}0,945 \\
(0,36)\end{array}$ & - \\
\hline$(-7,0,7)$ & $\begin{array}{r}-1,199 \\
(0,23)\end{array}$ & $\begin{array}{c}- \\
0,503 \\
(0,52)\end{array}$ & $\begin{array}{c}0,799 \\
(0,43)\end{array}$ & $\begin{array}{l}0,830 \\
(0,42)\end{array}$ & $\begin{array}{l}0,211 \\
(0,83)\end{array}$ & $\begin{array}{r}-1,311 \\
(0,20)\end{array}$ & $\begin{array}{l}0,386 \\
(0,70)\end{array}$ & $\begin{array}{l}1,328 \\
(0,20)\end{array}$ & $\begin{array}{l}2,332 \\
(0,02)\end{array}$ & $\begin{array}{c}- \\
3,657 \\
(0,00)\end{array}$ & $\begin{array}{c}0,870 \\
(0,40)\end{array}$ & - \\
\hline$(-8,0,8)$ & $\begin{array}{r}-1,184 \\
(0,24)\end{array}$ & $\begin{array}{c}- \\
0,453 \\
(0,65)\end{array}$ & $\begin{array}{c}0,543 \\
(0,59)\end{array}$ & $\begin{array}{l}0,455 \\
(0,65)\end{array}$ & $\begin{array}{l}0,230 \\
(0,82)\end{array}$ & $\begin{array}{r}-2,084 \\
(0,05)\end{array}$ & $\begin{array}{c}0,142 \\
(0,89)\end{array}$ & $\begin{array}{l}1,497 \\
(0,15)\end{array}$ & $\begin{array}{l}2,194 \\
(0,03)\end{array}$ & $\begin{array}{l}5,233 \\
(0,00)\end{array}$ & $\begin{array}{l}0,495 \\
(0,63)\end{array}$ & - \\
\hline$(-9,0,9)$ & $\begin{array}{r}-1,501 \\
(0,14)\end{array}$ & $\begin{array}{c}0,941 \\
(0,36)\end{array}$ & $\begin{array}{l}0,910 \\
(0,37)\end{array}$ & $\begin{array}{l}0,205 \\
(0,84)\end{array}$ & $\begin{array}{c}- \\
0,355 \\
(0,72) \\
\end{array}$ & $\begin{array}{c}-1,784 \\
(0,09)\end{array}$ & $\begin{array}{l}0,417 \\
(0,68)\end{array}$ & $\begin{array}{l}1,745 \\
(0,10)\end{array}$ & $\begin{array}{l}2,137 \\
(0,04)\end{array}$ & - & $\begin{array}{l}0,132 \\
(0,89) \\
\end{array}$ & - \\
\hline$(-10,0,10)$ & $\begin{array}{r}-1,289 \\
(0,20)\end{array}$ & $\begin{array}{c}- \\
0,439 \\
(0,66)\end{array}$ & $\begin{array}{l}0,784 \\
(0,44)\end{array}$ & $\begin{array}{c}- \\
0,054 \\
(0,96)\end{array}$ & $\begin{array}{c}- \\
0,260 \\
(0,80) \\
\end{array}$ & $\begin{array}{r}-1,505 \\
(0,15)\end{array}$ & $\begin{array}{l}0,565 \\
(0,58)\end{array}$ & $\begin{array}{l}1,335 \\
(0,20)\end{array}$ & $\begin{array}{l}1,876 \\
(0,07)\end{array}$ & $\begin{array}{c}- \\
4,284 \\
(0,00)\end{array}$ & $\begin{array}{c}- \\
0,296 \\
(0,77)\end{array}$ & - \\
\hline $\begin{array}{l}\mathrm{N}^{\circ} \text { de } \\
\text { ações }\end{array}$ & 74 & 17 & 21 & 17 & 19 & 20 & 15 & 15 & 30 & 14 & 15 & 9 \\
\hline
\end{tabular}

Nota. Fonte: Dados da Pesquisa, 2017. Os valores em () parênteses são referentes ao p - valor da estatística calculada, considerando o nível de $5 \%$ de significância"; os espaços com "-" são para os casos em que a distribuição dos retornos não é normal'2.

Os resultados em destaque correspondem aos testes que foram estatisticamente significativos, considerando o nível de $5 \%$ de significância. A Tabela 5 apresenta os resultados dos testes não paramétricos, sinais simples e sinais de Wilcoxon. Para esses casos, não se exige que os dados sejam distribuídos normalmente, ou seja, são mais flexíveis em relação à distribuição dos dados e são mais robustos a pequenas amostras quando comparados aos testes paramétricos (Rocha \& Delmaro, 2011). A primeira linha de cada janela de evento se refere ao teste de sinais simples, enquanto a segunda se refere ao teste de sinais de Wilcoxon:

Os resultados apresentados nas Tabelas 4 e 5 evidenciam que no primeiro ano de divulgação do ranking Global 100 (2005) não foi observado, de modo geral, significância estatística nos testes para se afirmar que a criação e anúncio do ranking causou algum efeito (positivo ou negativo) nos retornos das ações das empresas envolvidas. Exceto para a janela de 13 dias $(-6,0,6)$, que apresentou estatística significativa para o teste t, com t estatístico -2,024 e p-valor 0,04 e para o teste de sinais simples, com z estatístico -2,179 e p-valor 0,02.

Os anos subsequentes, de 2006 até 2009, não apresentaram significância estatística em nenhum dos testes utilizados. E também para este caso o evento não causou efeito nos retornos das ações das empresas, de maneira que os investidores não obtiveram ganhos ou perdas. Pode-se considerar que para estes casos há uma indicação de que mercado foi eficiente e a informação já estava precificada, conforme a definição de eficiência de mercado semiforte (Camargos \& Barbosa, 2003a; Fama, 1991; Forti et al., 2009). 
Tabela 5

Testes não Paramétricos: Sinais e Sinais de Wilcoxon

\begin{tabular}{|c|c|c|c|c|c|c|c|c|c|c|c|c|}
\hline Janela & 2005 & 2006 & 2007 & 2008 & 2009 & 2010 & 2011 & 2012 & 2013 & 2014 & 2015 & 2016 \\
\hline \multirow[b]{2}{*}{0} & $\begin{array}{l}1,721 \\
(0,13) \\
\end{array}$ & $\begin{array}{c}- \\
(0,63)\end{array}$ & $\begin{array}{c}-\overline{-} \\
(1,00)\end{array}$ & $\begin{array}{c}- \\
(0,33)\end{array}$ & $\begin{array}{c}-\overline{-} \\
(1,00)\end{array}$ & $\begin{array}{c}-\overline{1} \\
(0,11)\end{array}$ & $\begin{array}{c}- \\
(0,61)\end{array}$ & $\begin{array}{c}-\overline{-} \\
(1,00)\end{array}$ & $\begin{array}{l}1,278 \\
(0,20)\end{array}$ & $\begin{array}{c}- \\
(0,42)\end{array}$ & $\begin{array}{c}-\overline{-} \\
(1,00)\end{array}$ & $\begin{array}{c}- \\
(0,51)\end{array}$ \\
\hline & $\begin{array}{l}1,384 \\
(0,17) \\
\end{array}$ & $\begin{array}{r}-0,473 \\
(0,64) \\
\end{array}$ & $\begin{array}{r}0,035 \\
(0,97)\end{array}$ & $\begin{array}{l}0,947 \\
(0,35)\end{array}$ & $\begin{array}{r}-0,101 \\
(0,92)\end{array}$ & $\begin{array}{c}- \\
2,109 \\
(0,03 \\
\quad\end{array}$ & $\begin{array}{r}-0,937 \\
(0,34) \\
\end{array}$ & $\begin{array}{l}0,369 \\
(0,72)\end{array}$ & $\begin{array}{l}1,954 \\
(0,05)\end{array}$ & $\begin{array}{r}-0,753 \\
(0,46)\end{array}$ & $\begin{array}{r}-0,540 \\
(0,59) \\
\end{array}$ & $\begin{array}{l}1,540 \\
(0,13)\end{array}$ \\
\hline \multirow[b]{2}{*}{$(-1,0,1)$} & $\begin{array}{r}-1,491 \\
-13)\end{array}$ & $(0 \overline{33})$ & $(0 \overline{19})$ & $(1 \overline{0})$ & $(\overline{-})$ & $\left(\frac{-}{82}\right)$ & $(0 \overline{61})$ & $\overline{1}^{-}$ & 1,643 & $(0 \overline{79})$ & $(\overline{-})$ & $(\overline{0})$ \\
\hline & $\begin{array}{c}-1,169 \\
(0,24)\end{array}$ & $\begin{array}{c}-1,467 \\
(0,14)\end{array}$ & $\begin{array}{r}-1,077 \\
(0,29)\end{array}$ & $\begin{array}{c}-0,142 \\
(0,89)\end{array}$ & $\begin{array}{c}0,101 \\
(0,92)\end{array}$ & $\begin{array}{c}-1,549 \\
(0,12)\end{array}$ & $\begin{array}{c}-0,767 \\
(0,44)\end{array}$ & $\begin{array}{c}1,051 \\
(0,29)\end{array}$ & $\begin{array}{l}2,509 \\
(0,01)\end{array}$ & $\begin{array}{c}0,314 \\
(0,75)\end{array}$ & $\begin{array}{c}0,142 \\
(0,89)\end{array}$ & $\begin{array}{c}0,237 \\
(0,81)\end{array}$ \\
\hline \multirow{2}{*}{$(-2,0,2)$} & $\begin{array}{c}0,000 \\
(1,00)\end{array}$ & $(0, \overline{33})$ & $(0, \overline{38})$ & $(1, \overline{0})$ & $(0, \overline{6})$ & $(0, \overline{11})$ & $\begin{array}{c}- \\
(0,61)\end{array}$ & $(0, \overline{61})$ & $\begin{array}{l}1,643 \\
(0,10)\end{array}$ & $(1.00)$ & $(0 . \overline{61})$ & $\left(\begin{array}{c}- \\
(0.51)\end{array}\right.$ \\
\hline & $\begin{array}{c}0,361 \\
(0,72) \\
\end{array}$ & $\begin{array}{c}-0,947 \\
(0,35 \\
\end{array}$ & $\begin{array}{c}-0,799 \\
(0,43) \\
\end{array}$ & $\begin{array}{c}0,615 \\
(0,55) \\
\end{array}$ & $\begin{array}{r}-0,262 \\
(0,80) \\
\end{array}$ & $\begin{array}{r}-1,736 \\
(0,08) \\
\end{array}$ & $\begin{array}{r}-0,256 \\
(0,80) \\
\end{array}$ & $\begin{array}{r}0,028 \\
(0,98) \\
\end{array}$ & $\begin{array}{l}1,769 \\
(0,07) \\
\end{array}$ & $\begin{array}{r}-0,063 \\
(0,95) \\
\end{array}$ & $\begin{array}{r}-0,369 \\
(0,72) \\
\end{array}$ & $\begin{array}{r}1,896 \\
(0,05) \\
\end{array}$ \\
\hline \multirow{2}{*}{$(-3,0,3)$} & $\begin{array}{c}0,115 \\
(0,91)\end{array}$ & $\begin{array}{c}- \\
(0,63)\end{array}$ & $\begin{array}{c}- \\
(0,38)\end{array}$ & $(\overline{-}, \overline{0})$ & $(0, \overline{36})$ & $\begin{array}{c}- \\
(0,82)\end{array}$ & $\begin{array}{c}- \\
(0,61)\end{array}$ & $(0, \overline{30})$ & $\begin{array}{l}2,008 \\
(0,04)\end{array}$ & $\begin{array}{c}- \\
(0,42)\end{array}$ & $(0, \overline{30})$ & $\begin{array}{c}- \\
(0,51)\end{array}$ \\
\hline & $\begin{array}{l}0,005 \\
(0,99) \\
\end{array}$ & $\begin{array}{r}-0,663 \\
(0,52) \\
\end{array}$ & $\begin{array}{l}0,278 \\
(0,78) \\
\end{array}$ & $\begin{array}{l}0,379 \\
(0,71) \\
\end{array}$ & $\begin{array}{r}-0,905 \\
(0,37) \\
\end{array}$ & $\begin{array}{r}-0,392 \\
(0,70) \\
\end{array}$ & $\begin{array}{r}-0,199 \\
(0,84) \\
\end{array}$ & $\begin{array}{c}1,108 \\
(0,27) \\
\end{array}$ & $\begin{array}{l}1,604 \\
(0,11) \\
\end{array}$ & $\begin{array}{r}-1,507 \\
(0,13) \\
\end{array}$ & $\begin{array}{c}-0,426 \\
(0,68) \\
\end{array}$ & $\begin{array}{r}1,185 \\
(0,23) \\
\end{array}$ \\
\hline \multirow[b]{2}{*}{$(-4,04)$} & $\begin{array}{c}-0,574 \\
(0,56) \\
\end{array}$ & $(1, \overline{0})$ & $(1, \overline{0})$ & $\begin{array}{c}- \\
(0,63)\end{array}$ & $\begin{array}{c}- \\
(0,36)\end{array}$ & $(1, \overline{0})$ & $\begin{array}{c}-\overline{3} \\
(0,30)\end{array}$ & $\begin{array}{c}- \\
(0,61)\end{array}$ & $\begin{array}{l}0,183 \\
(0,85) \\
\end{array}$ & $\begin{array}{c}-\overline{18} \\
(0,18)\end{array}$ & $\begin{array}{c}- \\
(0,61)\end{array}$ & $\begin{array}{c}- \\
(0,51)\end{array}$ \\
\hline & $\begin{array}{r}-1,228 \\
(0,22) \\
\end{array}$ & $\begin{array}{r}-0,473 \\
(0,64) \\
\end{array}$ & $\begin{array}{l}0,695 \\
(0,49) \\
\end{array}$ & $\begin{array}{r}0,568 \\
(0,58) \\
\end{array}$ & $\begin{array}{r}-1,026 \\
(0,31) \\
\end{array}$ & $\begin{array}{r}-0,355 \\
(0,73) \\
\end{array}$ & $\begin{array}{r}0,483 \\
(0,64) \\
\end{array}$ & $\begin{array}{c}0,767 \\
(0,45) \\
\end{array}$ & $\begin{array}{l}1,275 \\
(0,20) \\
\end{array}$ & $\begin{array}{c}- \\
2,323 \\
(0,01 \\
)\end{array}$ & $\begin{array}{l}0,767 \\
(0,45) \\
\end{array}$ & $\begin{array}{l}1,185 \\
(0,23) \\
\end{array}$ \\
\hline \multirow{2}{*}{$(-5,0,5)$} & $\begin{array}{r}-1,262 \\
(0,20) \\
\end{array}$ & $(1, \overline{0})$ & $(0,-\overline{66})$ & $(0, \overline{63})$ & $(1, \overline{-})$ & $(1, \overline{-})$ & $(0, \overline{6})$ & $(0, \overline{30})$ & $\begin{array}{c}0,548 \\
(0,58) \\
\end{array}$ & $\begin{array}{c}(0,01 \\
)\end{array}$ & $(0, \overline{30})$ & $(1, \overline{-})$ \\
\hline & $\begin{array}{r}-1,385 \\
(0,17) \\
\end{array}$ & $\begin{array}{r}0,331 \\
(0,74) \\
\end{array}$ & $\begin{array}{l}1,043 \\
(0,30) \\
\end{array}$ & $\begin{array}{r}0,237 \\
(0,82) \\
\end{array}$ & $\begin{array}{l}0,342 \\
(0,74) \\
\end{array}$ & $\begin{array}{c}-0,467 \\
(), 65) \\
\end{array}$ & $\begin{array}{r}0,540 \\
(0,58) \\
\end{array}$ & $\begin{array}{l}1,392 \\
(0,17) \\
\end{array}$ & $\begin{array}{c}0,740 \\
(0,46) \\
\end{array}$ & $\begin{array}{c}- \\
2,825 \\
(0,00 \\
)\end{array}$ & $\begin{array}{c}0,596 \\
(0,56) \\
\end{array}$ & $\begin{array}{r}-0,237 \\
(0,81) \\
\end{array}$ \\
\hline \multirow{2}{*}{$(-6,06)$} & $\begin{array}{c}- \\
2,179 \\
(0,02)\end{array}$ & $(1, \overline{0})$ & $(0, \overline{66})$ & $(1, \overline{0} 0)$ & $(1, \overline{0} 0)$ & $(0, \overline{82})$ & $(0, \overline{61})$ & $(0, \overline{30})$ & $\begin{array}{r}0,548 \\
(0,58) \\
\end{array}$ & $\begin{array}{c}(0,01 \\
)\end{array}$ & $(1, \overline{0})$ & $(1, \overline{0})$ \\
\hline & $\begin{array}{r}-1,859 \\
(0,06) \\
\end{array}$ & $\begin{array}{r}-0,284 \\
(0,78) \\
\end{array}$ & $\begin{array}{r}0,521 \\
(0,61) \\
\end{array}$ & $\begin{array}{r}-0,142 \\
(0,89) \\
\end{array}$ & $\begin{array}{r}-0,423 \\
(0,68) \\
\end{array}$ & $\begin{array}{r}-0,952 \\
(0,35) \\
\end{array}$ & $\begin{array}{r}-0,256 \\
(0,80) \\
\end{array}$ & $\begin{array}{l}1,448 \\
(0,15) \\
\end{array}$ & $\begin{array}{l}1,358 \\
(0,17) \\
\end{array}$ & $\begin{array}{c}-\overline{6} \\
2,637 \\
(0,00 \\
)\end{array}$ & $\begin{array}{c}0,880 \\
(0,39) \\
\end{array}$ & $\begin{array}{r}0,711 \\
(0,48) \\
\end{array}$ \\
\hline \multirow{2}{*}{$(-7,0,7)$} & $\begin{array}{r}-1,721 \\
(0,08) \\
\end{array}$ & $(0, \overline{63})$ & $(1, \overline{0})$ & $(1, \overline{0})$ & $(0, \overline{65})$ & $(0, \overline{50})$ & $(0, \overline{61})$ & $(0, \overline{61})$ & $\begin{array}{l}0,913 \\
(0,36)\end{array}$ & $(0,01$ & $(0, \overline{61})$ & $(0, \overline{51})$ \\
\hline & $\begin{array}{r}-1,034 \\
(0,30) \\
\end{array}$ & $\begin{array}{r}-0,568 \\
(0,58) \\
\end{array}$ & $\begin{array}{c}0,626 \\
(0,54)\end{array}$ & $\begin{array}{l}0,615 \\
(0,55) \\
\end{array}$ & $\begin{array}{l}0,060 \\
(0,95) \\
\end{array}$ & $\begin{array}{r}-0,952 \\
(0,35)\end{array}$ & $\begin{array}{r}0,199 \\
(0,84) \\
\end{array}$ & $\begin{array}{l}1,392 \\
(0,17)\end{array}$ & $\begin{array}{l}2,201 \\
(0,03)\end{array}$ & $\begin{array}{c}2,825 \\
(0,00 \\
)\end{array}$ & $\begin{array}{l}0,767 \\
(0,45) \\
\end{array}$ & $\begin{array}{r}0,711 \\
(0,48) \\
\end{array}$ \\
\hline \multirow{2}{*}{$(-8,0,8)$} & $\begin{array}{r}-1,491 \\
(0,13) \\
\end{array}$ & $(1, \overline{-})$ & $\begin{array}{c}- \\
(1,00)\end{array}$ & $(1, \overline{0})$ & $(1, \overline{0})$ & $(0, \overline{26})$ & $\begin{array}{c}- \\
(1,00)\end{array}$ & $(0, \overline{61})$ & $\begin{array}{c}0,913 \\
(0,36)\end{array}$ & $\begin{array}{c}- \\
(0,00 \\
)\end{array}$ & $(1, \overline{0})$ & $(0, \overline{51})$ \\
\hline & $\begin{array}{r}-1,142 \\
(0,25) \\
\end{array}$ & $\begin{array}{r}-0,473 \\
(0,63) \\
\end{array}$ & $\begin{array}{l}0,626 \\
(0,54) \\
\end{array}$ & $\begin{array}{r}0,331 \\
(0,75) \\
\end{array}$ & $\begin{array}{c}0,181 \\
(0,86) \\
\end{array}$ & $\begin{array}{r}-1,736 \\
(0,08) \\
\end{array}$ & $\begin{array}{l}0,199 \\
(0,84) \\
\end{array}$ & $\begin{array}{l}1,221 \\
(0,23)\end{array}$ & $\begin{array}{c}1,872 \\
(0,06) \\
\end{array}$ & $\begin{array}{c}3, \overline{202} \\
(0,00 \\
)\end{array}$ & $\begin{array}{l}0,426 \\
(0,68) \\
\end{array}$ & $\begin{array}{l}1,422 \\
(0,15)\end{array}$ \\
\hline \multirow{2}{*}{$(-9,0,9)$} & $\begin{array}{r}-1,491 \\
(0,13) \\
\end{array}$ & $(0, \overline{63})$ & $(1, \overline{0})$ & $(0, \overline{63})$ & $(0, \overline{65})$ & $(0, \overline{50})$ & $(1, \overline{-})$ & $(0, \overline{30})$ & $\begin{array}{l}0,913 \\
(0,36)\end{array}$ & $\begin{array}{c}(0,00 \\
)\end{array}$ & $(1, \overline{-})$ & $(0, \overline{51})$ \\
\hline & $\begin{array}{r}-1,422 \\
(0,15) \\
\end{array}$ & $\begin{array}{r}-1,041 \\
(0,30)\end{array}$ & $\begin{array}{l}0,869 \\
(0,39)\end{array}$ & $\begin{array}{l}0,047 \\
(0,96) \\
\end{array}$ & $\begin{array}{r}-0,463 \\
(0,65)\end{array}$ & $\begin{array}{r}-1,213 \\
(0,23) \\
\end{array}$ & $\begin{array}{r}-0,256 \\
(0,80) \\
\end{array}$ & $\begin{array}{c}1,392 \\
(0,17)\end{array}$ & $\begin{array}{c}1,872 \\
(0,06) \\
\end{array}$ & $\begin{array}{c}-\overline{3} \\
3,202 \\
(0,00 \\
)\end{array}$ & $\begin{array}{r}-0,199 \\
(0,84)\end{array}$ & $\begin{array}{c}0,711 \\
(0,48)\end{array}$ \\
\hline \multirow{2}{*}{$(-10,0,10)$} & $\begin{array}{r}-1,491 \\
(0,13) \\
\end{array}$ & $(1, \overline{0})$ & $(0, \overline{6})$ & $\left(\begin{array}{c}- \\
(0,63)\end{array}\right.$ & $\begin{array}{c}- \\
(0,65)\end{array}$ & $(0, \overline{26})$ & $(0, \overline{61})$ & $(0, \overline{61})$ & $\begin{array}{r}0,183 \\
(0,85) \\
\end{array}$ & $(0,00$ & $(0, \overline{-})$ & $(1, \overline{0})$ \\
\hline & $\begin{array}{r}-1,142 \\
(0,25)\end{array}$ & $\begin{array}{c}-0,426 \\
(0,67)\end{array}$ & $\begin{array}{l}0,730 \\
(0,47)\end{array}$ & $\begin{array}{c}-0,237 \\
(0,82)\end{array}$ & $\begin{array}{c}-0,382 \\
(0,71)\end{array}$ & $\begin{array}{r}-1,064 \\
(0,29)\end{array}$ & $\begin{array}{l}0,028 \\
(0,98)\end{array}$ & $\begin{array}{l}1,051 \\
(0,29)\end{array}$ & $\begin{array}{l}1,440 \\
(0,15)\end{array}$ & $\begin{array}{c}- \\
3,139 \\
(0,00 \\
\quad\end{array}$ & $\begin{array}{r}-0,085 \\
(0,93)\end{array}$ & $\begin{array}{l}0,474 \\
(0,63)\end{array}$ \\
\hline $\begin{array}{l}\mathrm{N}^{\circ} \text { de } \\
\text { ações }\end{array}$ & 74 & 17 & 21 & 17 & 19 & 20 & 15 & 15 & 30 & 14 & 15 & 9 \\
\hline
\end{tabular}

Nota. Fonte: Dados da Pesquisa, 2017. Os valores em () parênteses correspondem ao p - valor da estatística calculada, considerando o nível de $5 \%$ de significância ${ }^{1}$; a primeira linha de cada janela é referente ao teste de sinais, enquanto que a segunda corresponde ao teste de sinais de Wilcoxon².

No ano de 2010, observa-se que houve significância estatística para o teste t e para o teste de sinais de Wilcoxon, na data de anúncio do ranking (data "0"), com estatísticas e p-valores -2,282 
$(0,03) ;-2,109(0,03)$, respectivamente; o teste de sinais simples não apresentou significância estatística. Esse resultado sugere que no dia do anúncio do ranking Global 100 no ano de 2010 os investidores com ações nas empresas incluídas reagiram de forma negativa. Resultado semelhante aos encontrados nas pesquisas realizadas por Anderson-Weir (2010) e Oberndorfer et al. (2013). Nas janelas acumuladas seguintes não se observou significância estatística nos testes e, dessa maneira, os preços das ações dessas empresas voltou ao preço de equilíbrio, de maneira que não possibilitou resultado anormal negativo ou positivo.

No ano de 2013 houve resultados significativos estatisticamente em mais de uma janela, inclusive na data 0 , dia da divulgação do ranking. Dessa forma, as janelas $(0),(-1,0,1),(-7,0,7),(-$ $8,0,8)$ e $(-9,0,9)$ foram significantes estatisticamente para o teste $t$, com t estatístico e $p$-valores $2,187(0,03) ; 2,961(0,00) ; 2,332(0,02) ; 2,194(0,03)$ e $2,137(0,04)$ respectivamente. No caso dos testes não paramétricos, as janelas que apresentaram significância estatística foram $(-1,0,1) ;(-3,0,3)$ e $(-7,0,7)$ com estatísticas e p-valores $2,509(0,01) ; 2,008(0,04)$ e $2,201(0,03)$, respectivamente.

Esse resultado apresenta que os retornos anormais das empresas que foram incluídas no ranking em 2013 foram positivos, acarretando em retornos anormais, resultado que confirma a eficiência de mercado semiforte discutida na literatura (Camargos \& Barbosa, 2003a; Fama, 1991; Forti et al., 2009). Essa evidenciação revela que o evento impactou os retornos desde a divulgação até a janela com nove dias. Dessa forma, o efeito do evento durou alguns dias após sua divulgação para que os retornos voltassem ao que já era esperado pelo mercado.

A reação favorável à informação, que aqui se refere à inclusão de empresas em um ranking que considera as empresas mais sustentáveis, revela que os preços das ações dessas empresas valorizaram acima do que era esperado pelo mercado acionário. Evidencia também, que os investidores têm despertado interesse em realizar investimentos em empresas que venham a desenvolver atividades ou destinam recursos voltados para o meio ambiente e para sociedade de um modo geral. Considera-se que esse feedback observado no mercado é importante para fortalecer o interesse das empresas em continuar executando atividades dessa natureza e para despertar o interesse de novos investidores.

O resultado referente à obtenção de retornos anormais positivos também pode ser encontrado nas pesquisas realizadas por Lyon e Shimshack (2015) e Murguia e Lence (2015). Esses autores argumentam que esse resultado positivo pode estar ligado a diversos fatores, dentre eles a reputação da marca, satisfação dos stakeholders, contribuição com o desenvolvimento sustentável, questões ligadas à ética e à moral. Outros autores evidenciam a vantagem competitiva como benefício para empresas que desempenham atividades de RSC e sustentáveis, podendo ser vistas dessa forma pelos acionistas/investidores (Schaeffer et al., 2012; Mutezo, 2014, Wang \& Chen, 2015; Madorran \& Garcia, 2016).

Outro ano de divulgação do ranking Global 100 que apresentou significância estatística foi 2014. De acordo com os resultados obtidos pelo teste $t$, as janelas que apresentaram significância foram: $(-4,0,4) ;(-5,0,5) ;(-6,0,6) ;(-7,0,7) ;(-8,0,8)$ e $(-10,0,10)$ com t estatístico e p-valores: $-2,342$ $(0,03) ;-3,104(0,00) ;-3,255(0,00) ;-3,657(0,00) ;-5,233(0,00)$ e $-4,284(0,00)$, respectivamente. Os testes não paramétrios apresentaram significância estatística paras as janelas $(-4,0,4) ;(-5,0,5)$; $(-$ $6,0,6) ;(-7,0,7) ;(-8,0,8) ;(-9,0,9)$ e $(-10,0,10)$, destas, o teste de sinais só não apresentou significância na janela $(-4,0,4)$.

Como os CARs do ano de 2014 formam uma amostra pequena, o teste de sinais simples expõe apenas o $p$-valor, pois a estatística segue uma binomial $k \sim(n ; 0,5)$. Por outro lado, o teste de sinais de Wilcoxon apresenta z estatístico para amostras pequenas e para as janelas citadas no parágrafo anterior. Para o teste de Wilcoxon as estatísticas calculadas juntamente com os p-valores foram respectivamente, $-2,323(0,01) ;-2,825(0,00) ;-2,637(0,00) ;-2,825(0,00) ;-3,202(0,00) ;-3,202$ $(0,00)$ e $-3,139(0,00)$.

O resultado do ano de 2014 foi oposto ao observado no ano de 2013, visto que os investidores das empresas incluídas no ranking reagiram de maneira negativa à informação, fazendo com que os retornos dessas ações ficassem abaixo do esperado e assim, constituindo-se de retornos anormais negativos. Esse resultado é semelhante ao encontrado no ano de divulgação do ranking de 2010 e também aos resultados dos ARs para cada dia do evento, que conforme a Tabela 6 também foram predominantemente negativos.

Esse resultado evidencia que o mercado pode não responder de forma positiva a esse tipo de informação. Seguindo a corrente tradicionalista, o desempenho relacionado à RSC e à sustentabilidade pode levar à redução de lucros e até desvantagens competitivas (Oberndorfer et al., 2013). Além disso, os mesmos autores argumentam que os possíveis ganhos com reputação e as reduções de custos não foram recompensados financeiramente. Neste caso, os investidores 
acreditam na perda financeira ao destinar recursos para questões de RSC ou de sustentabilidade, o avaliam como ação puramente simbólica, sendo caracterizado como reação a pressões institucionais.

Isso porque, devido as características de determinado ambiente, bem como a cobrança da sociedade para que sejam utilizados e/ou desenvolvidos processos que gerem menos impactos ao meio ambiente, ou que sejam realizados investimentos visando diminuir danos causados. Observase também a influência do mimetismo, no sentido de que algumas dessas corporações não possuem ações sustentáveis efetivas, mas apenas copiam projetos e investimentos realizados por outras organizações, representando uma atividade simbólica decorrente de pressões sociais e institucionais.

A significância dos retornos anormais acumulados também foi testada nos diferentes setores dos quais as empresas da amostra são classificadas. O procedimento de análise por setor da indústria também foi utilizado nas pesquisas de Wang e Chen (2015) e Murguia e Lence (2015). Além disso, Schaeffer et al. (2012) evidenciaram a importância de analisar setores. Assim, o objetivo desse procedimento é identificar se o evento causou efeito diferente, considerando que existem setores mais poluidores do que outros.

O ranking Global 100 classifica as empresas pelos seus respectivos setores de acordo com o Global Industry Classification Standard-GICS. Aqui se utilizou a classificação de 31/08/2016. Dessa forma, existem 10 setores da economia: energia, materiais, industrial, bens de consumo, produtos de consumo, cuidados com a saúde, financeiros, tecnologias da informação, serviços de telecomunicações e utilidades.

\section{Tabela 6}

\section{Teste t para os CARs considerando os diferentes setores da indústria}

\begin{tabular}{|c|c|c|c|c|c|c|c|c|c|c|}
\hline Janela & Energia & Materiais & Industrial & $\begin{array}{c}\text { Bens de } \\
\text { consum } \\
\text { o }\end{array}$ & $\begin{array}{l}\text { Prod. De } \\
\text { consum } \\
\quad 0\end{array}$ & Saúde & Financ. & Tecn. & Telec. & Utilidades \\
\hline 0 & - & $\begin{array}{l}-0,654 \\
(0,52)\end{array}$ & - & $\begin{array}{l}-2,806 \\
(0,00)\end{array}$ & $\begin{array}{l}1,474 \\
(0,15)\end{array}$ & $\begin{array}{l}0,202 \\
(0,84)\end{array}$ & - & - & $\begin{array}{l}0,149 \\
(0,88)\end{array}$ & $\begin{array}{l}0,356 \\
(0,73)\end{array}$ \\
\hline$(-1,0,1)$ & - & $\begin{array}{l}-0,287 \\
(0,77)\end{array}$ & $\begin{array}{l}0,009 \\
(0,99)\end{array}$ & $\begin{array}{r}-2,330 \\
(0,03)\end{array}$ & $\begin{array}{l}0,854 \\
(0,40)\end{array}$ & $\begin{array}{l}-0,774 \\
(0,45)\end{array}$ & - & $\begin{array}{l}-0,957 \\
(0,35)\end{array}$ & $\begin{array}{l}-0,296 \\
(0,77)\end{array}$ & $\begin{array}{l}0,011 \\
(0,99)\end{array}$ \\
\hline$(-2,0,2)$ & - & $\begin{array}{l}-0,324 \\
(0,75)\end{array}$ & $\begin{array}{l}0,793 \\
(0,43)\end{array}$ & - & $\begin{array}{l}0,470 \\
(0,64)\end{array}$ & $\begin{array}{c}-1,272 \\
(0,21)\end{array}$ & - & $\begin{array}{l}0,075 \\
(0,94)\end{array}$ & $\begin{array}{l}-0,724 \\
(0,48)\end{array}$ & $\begin{array}{l}1,355 \\
(0,20)\end{array}$ \\
\hline$(-3,0,3)$ & - & $\begin{array}{l}-0,807 \\
(0,42)\end{array}$ & $\begin{array}{l}0,414 \\
(0,68)\end{array}$ & - & - & $\begin{array}{l}-0,565 \\
(0,58)\end{array}$ & - & $\begin{array}{l}-0,390 \\
(0,70)\end{array}$ & $\begin{array}{c}-1,992 \\
(0,07)\end{array}$ & $\begin{array}{l}0,130 \\
(0,90)\end{array}$ \\
\hline$(-4,0,4)$ & - & $\begin{array}{l}-1,604 \\
(0,12)\end{array}$ & $\begin{array}{l}0,659 \\
(0,51)\end{array}$ & - & $\begin{array}{l}-0,046 \\
(0,96)\end{array}$ & $\begin{array}{r}-0,700 \\
(0,49)\end{array}$ & - & $\begin{array}{l}-0,456 \\
(0,65)\end{array}$ & $\begin{array}{r}-1,443 \\
(0,17)\end{array}$ & $\begin{array}{l}0,317 \\
(0,75)\end{array}$ \\
\hline$(-5,0,5)$ & - & $\begin{array}{l}-0,663 \\
(0,51)\end{array}$ & $\begin{array}{l}0,751 \\
(0,46)\end{array}$ & - & $\begin{array}{l}-0,459 \\
(0,65)\end{array}$ & $\begin{array}{l}0,167 \\
(0,87)\end{array}$ & $\begin{array}{l}1,283 \\
(0,20)\end{array}$ & $\begin{array}{l}-1,586 \\
(0,12)\end{array}$ & $\begin{array}{r}-1,912 \\
(0,08)\end{array}$ & $\begin{array}{l}-0,760 \\
(0,46)\end{array}$ \\
\hline$(-6,0,6)$ & - & $\begin{array}{l}-0,971 \\
(0,34)\end{array}$ & $\begin{array}{l}0,487 \\
(0,63)\end{array}$ & $\begin{array}{l}0,206 \\
(0,84)\end{array}$ & $\begin{array}{l}-0,138 \\
(0,89)\end{array}$ & $\begin{array}{l}0,642 \\
(0,53)\end{array}$ & - & $\begin{array}{l}-1,131 \\
(0,27)\end{array}$ & $\begin{array}{r}-1,242 \\
(0,24)\end{array}$ & $\begin{array}{l}-0,498 \\
(0,62)\end{array}$ \\
\hline$(-7,0,7)$ & - & $\begin{array}{l}-0,489 \\
(0,63)\end{array}$ & $\begin{array}{l}0,701 \\
(0,49)\end{array}$ & - & $\begin{array}{l}-0,225 \\
(0,82)\end{array}$ & $\begin{array}{l}0,767 \\
(0,45)\end{array}$ & $\begin{array}{r}-0,100 \\
(0,92)\end{array}$ & $\begin{array}{r}-0,172 \\
(0,86)\end{array}$ & $\begin{array}{l}-0,538 \\
(0,60)\end{array}$ & $\begin{array}{l}-0,316 \\
(0,76)\end{array}$ \\
\hline$(-8,0,8)$ & - & $\begin{array}{l}-0,634 \\
(0,53)\end{array}$ & $\begin{array}{l}1,212 \\
(0,23)\end{array}$ & $\begin{array}{l}0,365 \\
(0,72)\end{array}$ & $\begin{array}{l}-1,293 \\
(0,21)\end{array}$ & $\begin{array}{l}0,785 \\
(0,44)\end{array}$ & $\begin{array}{l}-0,305 \\
(0,76)\end{array}$ & $\begin{array}{l}-0,855 \\
(0,40)\end{array}$ & $\begin{array}{l}-0,740 \\
(0,47)\end{array}$ & - \\
\hline$(-9,0,9)$ & - & $\begin{array}{l}-0,315 \\
(0,75)\end{array}$ & $\begin{array}{l}1,283 \\
(0,21)\end{array}$ & $\begin{array}{l}0,447 \\
(0,66)\end{array}$ & $\begin{array}{r}-1,450 \\
(0,16)\end{array}$ & $\begin{array}{l}0,317 \\
(0,75)\end{array}$ & $\begin{array}{l}-0,961 \\
(0,34)\end{array}$ & $\begin{array}{r}-1,066 \\
(0,29)\end{array}$ & - & $\begin{array}{l}-0,693 \\
(0,50)\end{array}$ \\
\hline $\begin{array}{l}(- \\
10,0,10)\end{array}$ & - & $\begin{array}{l}-0,223 \\
(0,82)\end{array}$ & $\begin{array}{l}1,298 \\
(0,20)\end{array}$ & $\begin{array}{l}0,904 \\
(0,37)\end{array}$ & $\begin{array}{r}-1,400 \\
(0,17)\end{array}$ & $\begin{array}{l}0,559 \\
(0,58)\end{array}$ & $\begin{array}{r}-1,029 \\
(0,31)\end{array}$ & $\begin{array}{l}-0,649 \\
(0,52)\end{array}$ & - & $\begin{array}{l}-0,958 \\
(0,35)\end{array}$ \\
\hline $\begin{array}{l}N^{\circ} \text { de } \\
\text { ações }\end{array}$ & 21 & 29 & 33 & 27 & 23 & 23 & 56 & 27 & 12 & 15 \\
\hline
\end{tabular}

Nota. Fonte: Dados da Pesquisa, 2017. Os valores em () parênteses correspondem a p-valor da estatística calculada considerando o nível de $5 \%$ de significância ${ }^{1}$. Prod. De consumo se refere ao setor produtos de consumo, Financ. Refere-se a Financeiros, Tecn. a Tecnologias e Telec. a Telecomunicações.

Os setores mais significativos em termos de quantidade de empresas incluídas nos rankings Global 100 são os seguintes: financeiros; industrial; materiais; bens de consumo; e tecnologia da Informação, com $21 \%(62), 13 \%$ (39), 11\% (33), 10\% (30) e 10\% (31), respectivamente. O setor financeiro, apesar de ser o mais representativo da amostra, não é, em termos de atividade, aquele 
que causa mais impacto ao ambiente. Entretanto, pela quantidade de empresas desse setor incluídas nos rankings, percebe-se o interesse dos bancos, serviços financeiros, seguros e imobiliários em ISR. A Tabela 6 traz os resultados para o teste t paramétrico, enquanto a Tabela 7 traz os resultados dos testes de sinais simples e de Wilcoxon não paramétricos:

Tabela 7

Testes não paramétricos de sinais simples e de sinais de Wilcoxon para os diferentes setores da indústria

\begin{tabular}{|c|c|c|c|c|c|c|c|c|c|c|c|}
\hline Janela & $\begin{array}{c}\text { Test } \\
\mathrm{e}\end{array}$ & Energia & Materiais & Industrial & $\begin{array}{c}\text { Bens de } \\
\text { consum } \\
\text { o }\end{array}$ & $\begin{array}{l}\text { Prod. De } \\
\text { consum } \\
\text { o }\end{array}$ & Saúde & Finan. & Tecn. & Telec. & Utilidades \\
\hline \multirow[b]{2}{*}{0} & S & $(0, \overline{6} 6)$ & 0,13 & $(1, \overline{0} 0)$ & $(0, \overline{2} 5)$ & $(1, \overline{0} 0)$ & $0, \overline{6} 8$ & $\begin{array}{l}0,935 \\
(0,35)\end{array}$ & $(0, \overline{7} 0)$ & $(0, \overline{7} 7)$ & $(1, \overline{0} 0)$ \\
\hline & W & $\begin{array}{l}0,521 \\
(0,60)\end{array}$ & $\begin{array}{l}0,065 \\
(0,95)\end{array}$ & $\begin{array}{l}0,393 \\
(0,70)\end{array}$ & $\begin{array}{r}-2,366 \\
(0,02)\end{array}$ & $\begin{array}{l}1,353 \\
(0,17)\end{array}$ & $\begin{array}{l}-0,015 \\
(0,98)\end{array}$ & $\begin{array}{l}1,293 \\
(0,19)\end{array}$ & $\begin{array}{l}0,709 \\
(0,48)\end{array}$ & $\begin{array}{l}-0,431 \\
(0,66)\end{array}$ & $\begin{array}{l}-0,369 \\
(0,71)\end{array}$ \\
\hline$(-1,0,1)$ & $\begin{array}{l}\mathrm{s} \\
\mathrm{W}\end{array}$ & $\begin{array}{l}(1, \overline{0} 0) \\
0,000 \\
(1,00) \\
\end{array}$ & $\begin{array}{l}(1, \overline{0} 0) \\
-0,043 \\
(0,96) \\
\end{array}$ & $\begin{array}{l}(1, \overline{0} 0) \\
0,339 \\
(0,73) \\
\end{array}$ & $\begin{array}{r}(0, \overline{2} 5) \\
-2,102 \\
(0,03) \\
\end{array}$ & $\begin{array}{l}(0, \overline{4} 0) \\
1,080 \\
(0,28) \\
\end{array}$ & $\begin{array}{l}(0, \overline{2} 1) \\
-0,928 \\
(0,35) \\
\end{array}$ & $\begin{array}{l}0,134 \\
(0,89) \\
0,551 \\
(0,58) \\
\end{array}$ & $\begin{array}{l}(1, \overline{0} 0) \\
-0,516 \\
(0,60) \\
\end{array}$ & $\begin{array}{l}(1, \overline{0} 0) \\
-0,431 \\
(0,66) \\
\end{array}$ & $\begin{array}{l}(0, \overline{3} 0) \\
-0,539 \\
(0,58) \\
\end{array}$ \\
\hline \multirow{2}{*}{$(-2,0,2)$} & S & $(0, \overline{3} 8)$ & $(0, \overline{7} 1)$ & $(1, \overline{0} 0)$ & $(0, \overline{1} 2)$ & $(0, \overline{6} 8)$ & $(0, \overline{6} 8)$ & $\begin{array}{l}-0,668 \\
(0,50)\end{array}$ & $(0, \overline{4} 4)$ & $(0, \overline{7} 7)$ & $(0, \overline{6} 1)$ \\
\hline & W & $\begin{array}{l}1,460 \\
(0,14) \\
\end{array}$ & $\begin{array}{r}-0,195 \\
(0,84) \\
\end{array}$ & $\begin{array}{l}0,589 \\
(0,55) \\
\end{array}$ & $\begin{array}{r}-1,718 \\
(0,08) \\
\end{array}$ & $\begin{array}{l}0,654 \\
(0,51) \\
\end{array}$ & $\begin{array}{r}-1,201 \\
(0,23) \\
\end{array}$ & $\begin{array}{r}-0,436 \\
(0,66) \\
\end{array}$ & $\begin{array}{r}-0,084 \\
(0,93) \\
\end{array}$ & $\begin{array}{r}-0,745 \\
(0,45) \\
\end{array}$ & $\begin{array}{l}1,221 \\
(0,22) \\
\end{array}$ \\
\hline \multirow{2}{*}{$(-3,0,3)$} & S & $(0, \overline{0} 8)$ & $(1, \overline{0} 0)$ & $(1, \overline{0} 0)$ & $(0, \overline{7} 0)$ & $(0, \overline{4} 0)$ & $(1, \overline{0} 0)$ & $\begin{array}{l}0,401 \\
(0,69)\end{array}$ & $(1, \overline{0} 0)$ & $(0, \overline{1} 4)$ & $(0, \overline{6} 1)$ \\
\hline & W & $\begin{array}{l}1,842 \\
(0,06)\end{array}$ & $\begin{array}{l}-0,367 \\
(0,71)\end{array}$ & $\begin{array}{l}0,018 \\
(0,98)\end{array}$ & $\begin{array}{r}-1,117 \\
(0,26)\end{array}$ & $\begin{array}{l}1,201 \\
(0,23)\end{array}$ & $\begin{array}{l}-0,502 \\
(0,61)\end{array}$ & $\begin{array}{l}0,665 \\
(0,50)\end{array}$ & $\begin{array}{l}-0,372 \\
(0,71)\end{array}$ & $\begin{array}{l}-\overline{0} \\
2,000 \\
(0,04)\end{array}$ & $\begin{array}{l}0,028 \\
(0,97)\end{array}$ \\
\hline \multirow{2}{*}{$(-4,04)$} & S & $(0, \overline{1} 9)$ & $(0, \overline{1} 3)$ & $\begin{array}{l}1,044 \\
(0,29)\end{array}$ & $(1, \overline{0} 0)$ & $(0, \overline{6} 8)$ & $(0, \overline{2} 1)$ & $\begin{array}{l}0,668 \\
(0,50)\end{array}$ & $(0, \overline{7} 0)$ & $(0, \overline{3} 9)$ & $(1, \overline{0} 0)$ \\
\hline & w & $\begin{array}{l}1,494 \\
(0,13) \\
\end{array}$ & $\begin{array}{r}-1,514 \\
(0,13) \\
\end{array}$ & $\begin{array}{r}0,589 \\
(0,55) \\
\end{array}$ & $\begin{array}{c}-0,372 \\
(0,71) \\
\end{array}$ & $\begin{array}{l}0,228 \\
(0,82) \\
\end{array}$ & $\begin{array}{l}-0,988 \\
(0,32) \\
\end{array}$ & $\begin{array}{r}0,583 \\
(0,56) \\
\end{array}$ & $\begin{array}{r}-0,420 \\
(0,67) \\
\end{array}$ & $\begin{array}{r}-1,530 \\
(0,12) \\
\end{array}$ & $\begin{array}{r}0,028 \\
(0,97) \\
\end{array}$ \\
\hline$(-5,0,5)$ & $\begin{array}{l}\mathrm{s} \\
\mathrm{W}\end{array}$ & $\begin{array}{l}(1, \overline{0} 0) \\
0,452 \\
(0,65) \\
\end{array}$ & $\begin{array}{l}(0, \overline{4} 6) \\
-0,778 \\
(0,44) \\
\end{array}$ & $\begin{array}{l}1,044 \\
(0,29) \\
0,643 \\
(0,52) \\
\end{array}$ & $\begin{array}{l}(0, \overline{7} 0) \\
-0,468 \\
(0,64) \\
\end{array}$ & $\begin{array}{l}(1, \overline{0} 0) \\
-0,015 \\
(0,98) \\
\end{array}$ & $\begin{array}{l}(1, \overline{0} 0) \\
0,106 \\
(0,91) \\
\end{array}$ & $\begin{array}{l}0,935 \\
(0,35) \\
0,967 \\
(0,33) \\
\end{array}$ & $\begin{array}{l}(0, \overline{4} 4) \\
-1,285 \\
(0,20) \\
\end{array}$ & $\begin{array}{l}(0, \overline{3} 9) \\
-1,608 \\
(0,11) \\
\end{array}$ & $\begin{array}{l}(1, \overline{0} 0) \\
-0,483 \\
(0,63) \\
\end{array}$ \\
\hline$(-6,06)$ & $\begin{array}{l}\mathrm{s} \\
\mathrm{W}\end{array}$ & $\begin{array}{l}(1, \overline{0} 0) \\
0,452 \\
(0,65)\end{array}$ & $\begin{array}{r}(0, \overline{7} 1) \\
-0,735 \\
(0,47)\end{array}$ & $\begin{array}{l}0,696 \\
(0,48) \\
0,178 \\
(0,86) \\
\end{array}$ & $\begin{array}{l}(1, \overline{0} 0) \\
-0,324 \\
(0,74)\end{array}$ & $\begin{array}{l}(0, \overline{4} 0) \\
0,684 \\
(0,49)\end{array}$ & $\begin{array}{l}(1, \overline{0} 0) \\
0,471 \\
(0,64)\end{array}$ & $\begin{array}{l}0,935 \\
-(0,35) \\
-0,893 \\
(0,37) \\
\end{array}$ & $\begin{array}{c}(0, \overline{4} 4) \\
-1,093 \\
(0,27)\end{array}$ & $\begin{array}{r}(0, \overline{1} 4) \\
-1,843 \\
(0,06)\end{array}$ & $\begin{array}{l}(0, \overline{3} 0) \\
-0,426 \\
(0,68) \\
\end{array}$ \\
\hline$(-7,0,7)$ & $\begin{array}{l}\mathrm{S} \\
\mathrm{W}\end{array}$ & $\begin{array}{l}(0, \overline{6} 6) \\
0,556 \\
(0,58) \\
\end{array}$ & $\begin{array}{l}(1, \overline{0} 0) \\
-0,454 \\
(0,65) \\
\end{array}$ & $\begin{array}{l}0,696 \\
(0,48) \\
0,589 \\
(0,55) \\
\end{array}$ & $\begin{array}{l}(0, \overline{4} 4) \\
-0,565 \\
(0,57) \\
\end{array}$ & $\begin{array}{l}(0, \overline{4} 0) \\
0,289 \\
(0,77) \\
\end{array}$ & $\begin{array}{l}(0, \overline{6} 8) \\
0,198 \\
(0,84)\end{array}$ & $\begin{array}{l}0,668 \\
(0,50) \\
0,126 \\
(0,90) \\
\end{array}$ & $\begin{array}{l}(0, \overline{7} 0) \\
0,012 \\
(0,99)\end{array}$ & $\begin{array}{l}(0, \overline{7} 7) \\
-0,667 \\
(0,50) \\
\end{array}$ & $\begin{array}{l}(0, \overline{6} 1) \\
0,028 \\
(0,97)\end{array}$ \\
\hline$(-8,0,8)$ & $\begin{array}{l}\mathrm{S} \\
\mathrm{W}\end{array}$ & $\begin{array}{l}(1, \overline{0} 0) \\
0,626 \\
(0,54) \\
\end{array}$ & $\begin{array}{c}(0, \overline{1} 3) \\
-0,778 \\
(0,44) \\
\end{array}$ & $\begin{array}{l}0,696 \\
(0,48) \\
1,018 \\
(0,30) \\
\end{array}$ & $\begin{array}{l}(0, \overline{7} 0) \\
-0,204 \\
(0,84) \\
\end{array}$ & $\begin{array}{r}(1, \overline{0} 0) \\
-1,080 \\
(0,28) \\
\end{array}$ & $\begin{array}{l}(0, \overline{4} 0) \\
0,106 \\
(0,91) \\
\end{array}$ & $\begin{array}{l}-0,134 \\
(0,89) \\
-0,355 \\
(0,72) \\
\end{array}$ & $\begin{array}{l}(1, \overline{0} 0) \\
-0,300 \\
(0,76) \\
\end{array}$ & $\begin{array}{l}(0, \overline{3} 9) \\
-1,216 \\
(0,22) \\
\end{array}$ & $\begin{array}{l}(0, \overline{6} 1) \\
-0,199 \\
(0,84) \\
\end{array}$ \\
\hline$(-9,0,9)$ & $\begin{array}{l}\mathrm{S} \\
\mathrm{W}\end{array}$ & $\begin{array}{l}(0, \overline{6} 6) \\
-0,139 \\
(0,89) \\
\end{array}$ & $\begin{array}{l}(1, \overline{0} 0) \\
-0,324 \\
(0,74)\end{array}$ & $\begin{array}{l}1,044 \\
(0,29) \\
1,126 \\
(0,26) \\
\end{array}$ & $\begin{array}{l}(1, \overline{0} 0) \\
0,180 \\
(0,86) \\
\end{array}$ & $\begin{array}{c}(0, \overline{6} 8) \\
-1,049 \\
(0,29)\end{array}$ & $\begin{array}{l}(0, \overline{4} 0) \\
0,046 \\
(0,96)\end{array}$ & $\begin{array}{l}-1,470 \\
(0,14) \\
-1,032 \\
(0,30) \\
\end{array}$ & $\begin{array}{l}(1, \overline{0} 0) \\
-0,685 \\
(0,49)\end{array}$ & $\begin{array}{l}(0, \overline{1} 4) \\
-1,530 \\
(0,12) \\
\end{array}$ & $\begin{array}{c}(0, \overline{6} 1) \\
-0,312 \\
(0,77) \\
\end{array}$ \\
\hline$(-$ & $\mathrm{S}$ & $(0, \overline{6} 6)$ & $(0, \overline{4} 6)$ & $\begin{array}{l}0,348 \\
(0,73)\end{array}$ & $(1, \overline{0} 0)$ & $(0, \overline{6} 8)$ & $(1, \overline{0} 0)$ & $\begin{array}{l}-0,935 \\
(0,35)\end{array}$ & $(0, \overline{7} 0)$ & $(0, \overline{1} 4)$ & $(0, \overline{6} 1)$ \\
\hline $10,0,10)$ & w & $\begin{array}{r}-0,695 \\
(0,49) \\
\end{array}$ & $\begin{array}{r}-0,324 \\
(0,74) \\
\end{array}$ & $\begin{array}{l}1,036 \\
(0,30) \\
\end{array}$ & $\begin{array}{l}0,637 \\
(0,52)\end{array}$ & $\begin{array}{c}-0,928 \\
(0,35) \\
\end{array}$ & $\begin{array}{l}0,106 \\
(0,91) \\
\end{array}$ & $\begin{array}{r}-0,961 \\
(0,34) \\
\end{array}$ & $\begin{array}{c}-0,324 \\
(0,74) \\
\end{array}$ & $\begin{array}{r}-1,843 \\
(0,06) \\
\end{array}$ & $\begin{array}{r}-0,767 \\
(0,44) \\
\end{array}$ \\
\hline $\begin{array}{l}N^{\circ} \text { de } \\
\text { ações }\end{array}$ & & 21 & 29 & 33 & 27 & 23 & 23 & 56 & 27 & 12 & 15 \\
\hline
\end{tabular}

Nota. Fonte: Dados da Pesquisa, 2017. Os valores em () parênteses correspondem a p-valor da estatística calculada considerando o nível de $5 \%$ de significância ${ }^{1}$; Prod. De consumo se refere ao setor produtos de consumo, Financ. Refere-se a Financeiros, Tecn. a Tecnologias e Telec. a Telecomunicações ${ }^{2}$; $\mathrm{S}$ se refere ao teste de sinais e $\mathrm{W}$ ao teste de sinais de Wilcoxon ${ }^{3}$.

Os espaços com um traço ( - ) são observados em alguns setores e foram usados porque a distribuição dos CARs da janela correspondente não é normalmente distribuída e neste caso não se pode utilizar o teste t. O setor de Energia, por exemplo, rejeitou a hipótese nula de distribuição normal em todas as janelas consideradas para o evento. A Tabela 7 traz os resultados para os testes de sinais simples e de Wilcoxon para os diferentes setores.

As Tabelas 6 e 7 expõem os resultados associados aos testes de significância dos CARs para cada janela de evento nos diferentes setores da indústria. Os resultados do anúncio de participação das empresas no ranking Global 100 não alteraram os retornos que já eram esperados, considerando 
os setores que as empresas estão inseridas. A única significância estatística observada foi nos testes t e teste de sinais de Wilcoxon no dia do evento (janela 0 ) e na janela $(-1,0,1)$ para o setor de Bens de Consumo, com estatísticas e p-valores: teste t $-2,806(0,00)$ para a janela 0 e $-2,330(0,03)$ para a janela $(-1,0,1)$. Já o os $z$ estatísticos e $p$-valores do teste de sinais de Wilcoxon foram $-2,366(0,02)$ para a janela 0 e $-2,102(0,03)$.

O setor de Bens de Consumo é constituído por empresas dos grupos: automóveis e componentes, consumo durável e vestuário, serviços do consumidor, mídia e varejo. O setor de Telecomunicações apresentou significância no teste de sinais de Wilcoxon na janela $(-3,0,3)$ com z estatístico $-2,000$ e p-valor $(0,04)$. Os outros testes realizados não apresentaram significância estatística nas demais janelas consideradas. Os resultados revelam que o efeito do evento nos setores não foi, de maneira geral, significativo, e que o os investidores do setor de bens de consumo tiveram uma perda financeira, pois em duas janelas observaram-se retorno anormal negativo e significativo.

Com a análise por setor pretendeu-se identificar se a reação do mercado frente à inclusão das empresas no ranking aconteceu de forma diferente, considerando que existem setores mais poluidores. Dessa forma, ações sustentáveis oriundas das empresas destes setores poderiam gerar novas percepções para o mercado. Entretanto, para a amostra utilizada, não se constatou efeito positivo ou negativo, com exceção do setor de bens de consumo. Apesar da decorrência de uma reação negativa para este setor em diferentes espaços temporais considerados, essa reação se dissipou ao longo do tempo. Portanto, de maneira geral, não houve retornos anormais analisando os diferentes setores da indústria.

Os resultados desta pesquisa em relação aos setores apoiam a Teoria de Eficiência de Mercado semiforte e divergem dos obtidos por Wang e Chen (2015) e Murguia e Lence (2015), pois não se constatou significância estatística nos testes exceto na data "0" e na janela $(-1,0,1)$ para o setor de Bens de Consumo. Wang e Chen (2015) não encontraram significância estatística nos CARs e ARs no dia do evento (data " 0 "), mas relatam significâncias estatísticas, tanto positivas quanto negativas em dias anteriores e posteriores ao evento.

No tocante aos resultados obtidos por Murguia e Lence (2015), as especificações dos modelos apresentam que as empresas de setores considerados "pesados" reagem de maneira inferior aos setores considerados "não pesados", pois os autores encontraram significância estatística para o caso desses últimos. A justificativa apresentada por Murguia e Lence refere-se ao fato dos setores "não pesados" terem maiores oportunidades de melhorar o desempenho ambiental com baixo custo, quando comparados a setores "pesados" que possuem uma matriz energética com baixa elasticidade de substituição.

Por fim, os últimos testes foram realizados considerando todos os eventos e todas as ações da amostra, para então responder ao objetivo da pesquisa bem como as hipóteses lançadas. A Tabela 8 traz as estatísticas e os p-valores para cada teste e janela:

\section{Tabela 8}

\section{Testes de Significância para todos os eventos e ações da amostra}

\begin{tabular}{|c|c|c|c|c|c|c|c|c|c|c|c|}
\hline Janelas & 0 & $-1,0,1$ & $-2,0,2$ & $-3,0,3$ & $-4,0,4$ & $-5,0,5$ & $-6,0,6$ & $-7,0,7$ & $-8,0,8$ & $-9,0,9$ & $-10,0,10$ \\
\hline Teste $\mathrm{t}$ & $\begin{array}{l}0,835 \\
(0,40)\end{array}$ & $\begin{array}{c}-0,238 \\
(0,81)\end{array}$ & $\begin{array}{l}0,353 \\
(0,72)\end{array}$ & $\begin{array}{l}0,525 \\
(0,60)\end{array}$ & $\begin{array}{l}0,561 \\
(0,57)\end{array}$ & $\begin{array}{l}0,615 \\
(0,54)\end{array}$ & $\begin{array}{r}-0,160 \\
(0,87)\end{array}$ & $\begin{array}{c}0,741 \\
(0,46)\end{array}$ & $\begin{array}{l}0,444 \\
(0,66)\end{array}$ & $\begin{array}{l}0,172 \\
(0,86)\end{array}$ & $\begin{array}{l}0,231 \\
(0,82)\end{array}$ \\
\hline Sinais & $\begin{array}{l}0,429 \\
(0,67)\end{array}$ & $\begin{array}{c}-0,920 \\
(0,36)\end{array}$ & $\begin{array}{r}-1,042 \\
(0,30)\end{array}$ & $\begin{array}{c}-0,061 \\
(0,95)\end{array}$ & $\begin{array}{l}0,000 \\
(1,00)\end{array}$ & $\begin{array}{l}0,000 \\
(1,00)\end{array}$ & $\begin{array}{r}-1,042 \\
(0,30)\end{array}$ & $\begin{array}{l}0,552 \\
(0,58)\end{array}$ & $\begin{array}{r}-1,165 \\
(0,24)\end{array}$ & $\begin{array}{r}-1,533 \\
(0,12)\end{array}$ & $\begin{array}{r}-1,778 \\
(0,07)\end{array}$ \\
\hline Wilcoxon & $\begin{array}{l}0,544 \\
(0,58)\end{array}$ & $\begin{array}{c}-0,789 \\
(0,43)\end{array}$ & $\begin{array}{c}-0,223 \\
(0,82)\end{array}$ & $\begin{array}{c}-0,024 \\
(0,98)\end{array}$ & $\begin{array}{c}-0,090 \\
(0,93)\end{array}$ & $\begin{array}{c}-0,359 \\
(0,72)\end{array}$ & $\begin{array}{c}-0,966 \\
(0,33)\end{array}$ & $\begin{array}{l}0,196 \\
(0,84)\end{array}$ & $\begin{array}{r}-0,495 \\
(0,62)\end{array}$ & $\begin{array}{c}-1,088 \\
(), 28)\end{array}$ & $\begin{array}{r}-1,024 \\
(0,30)\end{array}$ \\
\hline $\begin{array}{l}N^{\circ} \text { de } \\
\text { ações }\end{array}$ & 266 & 266 & 266 & 266 & 266 & 266 & 266 & 266 & 266 & 266 & 266 \\
\hline
\end{tabular}

Nota. Fonte: Dados da Pesquisa, 2017. Os valores em () parênteses correspondem a p-valor da estatística calculada, considerando o nível de $5 \%$ de significância.

A Tabela 8 exibe os resultados dos testes de significância para os CARs de todas as ações da amostra em todas as janelas consideradas. Conforme se observa, os testes não apresentaram significância estatística em nenhuma das janelas, demonstrando que os CARs não são estatisticamente diferentes de 0 e, nesse sentido, os retornos são sofreram alterações, pois não houve ganho ou perda anormal. Dessa forma, o evento estudado, ou seja, as divulgações dos rankings Globais 100 com as 100 empresas mais sustentáveis do mundo, não possibilitou retornos anormais para os investidores das empresas incluídas nesse ranking desde a sua criação em 2005, até a última divulgação em 2016. Com esse resultado, tem-se uma indicação de que a informação 
de divulgação dos rankings aqui estudada já estava precificada nos títulos e dessa maneira, o resultado sugere apoio a hipótese de mercado eficiente na sua forma semiforte.

No tocante à hipótese de pesquisa, esta não pode ser confirmada, pois os resultados demonstraram, de forma geral, que não houve retornos anormais positivos quanto ao anúncio de inclusão das empresas nos rankings Global 100. O resultado dessa pesquisa se assemelha aos obtidos nos estudos realizados por Curran e Moran (2007), Cheung (2011), Schaeffer et al. (2012) e Wang e Chen (2015), os quais utilizaram como objeto de investigação índices que reúnem empresas com desempenhos em atividades de RSC e sustentabilidade. Ademais, os autores citados não encontraram relações significativas para afirmar que o engajamento em atividades sociais e ambientais acarreta em ganho financeiro.

No que se refere ao objetivo da pesquisa, que foi analisar o efeito causado nos retornos das ações das empresas após a divulgação de inclusão no ranking Global 100, este pode ser respondido da seguinte forma: o anuncio de inclusão das empresas no ranking Global 100 não causou efeito nos retornos das ações das empresas incluídas. Nesse sentido, não houve ganhos anormais ou perdas. Apesar de ter sido identificada significância estatística em algumas janelas quando considerada a divulgação do ranking por ano e por setor, esse mesmo resultado não foi obtido quando se realizou os testes com todas as ações da amostra. Assim, os retornos anormais acumulados são considerados estatisticamente iguais a 0.

Contudo, os resultados aqui observados não implicam que o ISR em atividades de RSC e sustentabilidade bem como a compra de ações de empresas incluídas em índices sustentáveis não possam trazer benefícios para as empresas e/ou para os investidores. Os esforços para desenvolver a prática de RSC devem ser realizados, pois têm um efeito na criação de valor (Madorran \& Garcia, 2016). Esses investimentos têm crescido nos últimos anos em todo o planeta, de modo que algumas empresas têm percebido a importância de destinar recursos para essas questões (GSIA, 2014).

Além disso, ISR é amplamente reconhecido como uma ferramenta estratégica que permite às empresas adquirir vantagem competitiva, pois se torna um diferencial (Mutezo, 2014). Além deste aspecto, o engajamento em atividades de RSC e sustentabilidade podem melhorar a reputação das empresas e facilitar a obtenção de recursos para seu funcionamento (Wang \& Chen, 2015; Madorran \& Garcia, 2016). Desse modo, essas questões podem, mesmo que em longo prazo, trazer uma melhoria no desempenho financeiro e oportunizar a criação de valor para os acionistas/investidores.

No entanto, questões associadas à reputação e à vantagem competitiva costumam estar interligadas. Quando a reputação da organização não está em um nível desejável para os stakeholders que estão envolvidos diretamente no seu funcionamento, o reconhecimento de que a empresa realiza atividade social e sustentável não terá grande impacto, no sentido de poder ser percebida no desempenho financeiro e de mercado (Alshammari, 2015). Entretanto, quando determinada organização tem uma boa reputação estabelecida e aumenta seu engajamento em atividades sociais e sustentáveis, a expectativa é obter uma vantagem competitiva e um melhor desempenho financeiro.

Dessa maneira, Mutezo (2014) traz uma reflexão sobre o que representa o ISR para os investidores, visto que essa preocupação se dá por diversas razões, pois os investidores querem investir com responsabilidade, muitas vezes, em empresas que desempenham atividades de RSC e sustentáveis, mas também querem e precisam obter, simultaneamente, bons retornos financeiros. Nesse sentido, levanta-se a questão de saber se o ISR proporciona maiores lucros ou apenas gera maiores custos. Há autores, como já mencionados nesta pesquisa, que defendem o aumento dos lucros e resultados positivos, enquanto outros afirmam ser desvantajoso.

Além disso, deve-se considerar que algumas empresas realizam atividades consideradas sustentáveis, tendo em vista a natureza da sua própria atividade. Ou seja, órgãos regulatórios fiscalizam e solicitam que esse tipo de engajamento seja realizado, visando diminuir possíveis danos causados. Nesse sentido, a reputação das corporações é considerada importante e relevante para que investidores se sintam seguros em aplicar seus recursos nestas empresas. Entretanto, vale ressaltar que algumas atividades podem ser realizadas apenas para cumprimento de leis.

Ainda nessa direção, fazendo um regaste à Teoria Institucional, práticas que estão institucionalizadas em um determinado ambiente fazem com que organizações as adotem visando sobrevivência (DiMaggio \& Powell, 2005), como pode ser o caso de práticas sustentáveis e de RSC adotadas por empresas já legitimadas neste ambiente. Essas questões são levantadas como possíveis justificativas para a não alteração do preço das ações das empresas analisadas nesta pesquisa quanto à inclusão em um ranking verde.

Em termos de implicações gerenciais, considerando a amostra e o ranking utilizado, participar de uma classificação que considera aspectos sustentáveis e sociais das corporações, não gera 
impactos no mercado a ponto de alterar o comportamento dos preços das ações. Por outro lado, pode-se afirmar, com base nos testes realizados, que tal informação já havia sido precificada.

Em termos acadêmicos, procurou-se desenvolver uma discussão da literatura sobre a eficiência de mercado e responsabilidade social corporativa associada ao desempenho financeiro das organizações. Além disso, buscou-se apresentar uma evidência empírica, considerando o envolvimento de empresas de diversos países em um ranking associado a sustentabilidade, elaborado por uma empresa internacional de mídia e pesquisa que ainda é pouco explorado pela comunidade acadêmica. Considera-se importante o estudo do efeito de informações voltadas à sustentabilidade e que esse tipo de informação possa influenciar a precificação de ações.

\section{Considerações Finais}

Essa pesquisa teve como objetivo analisar o efeito causado nos retornos das ações das empresas após a divulgação de inclusão no ranking Global 100. Para responder ao objetivo e a hipótese de pesquisa estabelecida, utilizou-se como metodologia o estudo de eventos, que com base na hipótese de mercado eficiente semiforte, tem a finalidade de identificar a reação do mercado a novas informações, de maneira que seja possível identificar se a informação acarretou em ganho anormal ou perda de valor significativo, ou se já estava precificada e os retornos anormais foram iguais a zero.

Dessa forma, o evento estudado, ou seja, as divulgações dos rankings Global 100 com as 100 empresas sustentáveis, não possibilitou retornos anormais para os investidores das empresas incluídas nesse ranking desde a sua criação em 2005, até a última divulgação em 2016. Com esse resultado, tem-se uma indicação de que a informação de divulgação dos rankings aqui estudada já estava precificada nos títulos e, dessa maneira, o resultado sugere apoio a hipótese de mercado eficiente na sua forma semiforte, conforme (Belo \& Brasil, 2006; Fama, 1970; 1991; Marques et al., 2015).

Os setores foram analisados com o objetivo de identificar se o evento causou efeito de maneira diferente entre eles. Os resultados não demonstraram retornos anormais significativos. Por fim, realizou-se a análise conjunta de todos os eventos e ações da amostra. Os resultados dos testes não apresentaram significância estatística nas janelas consideradas. Assim, respondendo ao objetivo da pesquisa, o evento não causou efeito positivo ou negativo nos retornos das ações. Para o caso da divulgação desse ranking, tem-se uma indicação de apoio a eficiência de mercado semiforte. No que se refere à hipótese $H_{1}$ estabelecida, esta não pode ser confirmada, pois não se identificou efeito positivo ou negativo.

Este resultado não implica que os ISRs não devem ser realizados, pois como mencionado anteriormente, eles têm crescido nos últimos anos. Além disso, é necessário que as corporações realizem estes tipos de investimentos para minimizar os dados causados por suas próprias atividades. Dessa forma, essa pesquisa buscou contribuir com mais uma evidência empírica da relação entre RSC e sustentável e o desempenho financeiro das empresas, representado aqui pelos retornos das ações, considerando uma amostra composta por empresas de diferentes países e setores.

Percebe-se que as informações associadas à RSC, ISR e sustentabilidade são importantes e necessárias. Entretanto, também são necessárias formas alternativas de apresentação desse engajamento por parte das empresas, com enfoque no disclosure das atividades realizadas, para que estas sejam efetivamente percebidas pelo mercado.

Cabe ressaltar que as evidências apresentadas devem ser observadas levando em consideração as limitações referentes à amostra, pois muitas empresas não dispunham ou não divulgaram os dados necessários. Ademais, a própria metodologia utilizada pode ser considerada um fator limitante, pois muitos aspectos podem não ser capturados pelos métodos aplicados. Por fim, decisões tomadas pelos pesquisadores durante a realização do trabalho em relação aos métodos de estimação, janela de estimação e janela de evento também podem ser enquadrados nesse quesito.

Dessa maneira, sugere-se que novas pesquisas sejam realizadas, utilizando o Global 100, pois é um ranking ainda pouco explorado e investigado academicamente. É possível ainda, nesse sentido, realizar estudos considerando variáveis contábeis e realizar comparações com outros índices e rankings. Além disso, pode-se realizar comparações entre países, utilizando estudo de eventos, buscando identificar quais os benefícios ou impactos gerados pelas atividades sociais e ambientais no desempenho financeiro das empresas. 
O efeito da informação de sustentabilidade corporativa nos retornos das ações: análise de empresas incluídas no ranking Global 100

\section{Notas}

1.Agradecemos as contribuições dos avaliadores, pois foram importantes na melhoria da qualidade do trabalho.

\section{Referências}

Alshammari, M. (2015). Corporate Social Responsibility and Firm Performance: The Moderating Role of Reputation and Institutional Investors. International Journal of Business and Management, 10(6), 15-28.

Anderson-Weir, C. H. (2010). How does the stock market react to corporate environmental news?. Undergraduate Economic Review, 6(1), 1-31.

Arantes, E. (2006). Investimento em responsabilidade social e sua relação com o desempenho econômico das empresas. Conhecimento Interativo, 2(1), p. 03-09.

Belo, N. M., \& Brasil, H. G. (2006). Assimetria informacional e eficiência semiforte do mercado. Revista de Administração de Empresas, 46(Spe), 48-57.

Bolsa de Valores, Mercadorias \& Futuros. Indice de Sustentabilidade Empresarial. Recuperado em 17 maio, 2016 de <http://isebvmf.com.br/>

Brooks, C. (2008). Introductory econometrics for finance. Cambridge: Cambridge university press.

Brown, S. J., \& Warner, J. B. (1985). Using daily stock returns: The case of event studies. Journal of financial economics, 14(1), 3-31.

Camargos, M. A., \& Barbosa, F. V. (2003a). Estudos de evento: teoria e operacionalização. Caderno de Pesquisa em Administração, 10(3), 1-20.

Camargos, M. A., \& Barbosa, F. V. (2003b). Teoria e evidência da eficiência informacional do mercado de capitais brasileiro. Caderno de pesquisas em administração, 10(1), 41-55.

Campbell, J. Y., Mackinlay, A. C., \& Lo, A. W. C. (1997). The econometrics of financial markets. Princeton University press.

Campbell, J. L. (2007). Why would corporations behave in socially responsible ways? An institutional theory of corporate social responsibility. Academy of management Review, 32(3), p. 946-967.

Cheung, A. W. K. (2011). Do stock investors value corporate sustainability? Evidence from an event study. Journal of Business Ethics, 99(2), 145-165.

Claro, P. B. O., \& Claro, D. P. (2014). Sustentabilidade estratégica: existe retorno no longo prazo? Revista de Administração, 49(2), p. 429-440.

CMMAD - Comissão Mundial sobre Meio Ambiente e Desenvolvimento. (1991). Nosso futuro comum. Rio de Janeiro: Editora da Fundação Getúlio Vargas.

Corporate Knights. The 2015 Global 100: Overview of Methodology. Recuperado em 05 março, 2016 de <www.global100.org $>$

Curran, M. M., \& Moran, D. (2007). Impact of the FTSE4Good Index on firm price: An event study. Journal of environmental management, 82(4), 529-537.

Dimaggio, P. J., \& Powell, W. W. (2005). A Gaiola de Ferro Revisitada: Isomorfismo Institucional e Racionalidade Coletiva nos Campos Organizacionais. RAE-Revista de Administração de Empresas, 45(2), 74-89.Donaldson, T., \& Preston, L. E. (1995). The stakeholder theory of the Corporation: concepts, evidence, and implications. Academy of Management Review, 20(1), 65-91.

Dourado, G. A., \& Tabak, B. M. (2014). Teste da Hipótese de Mercados Adaptativos para o Brasil. Revista Brasileira de Finanças, 12(4), 517-553.

Fama, E. F. (1970). Efficient capital markets: A review of theory and empirical work. The journal of Finance, 25(2), 383-417.

Fama, E. F. (1991). Efficient capital markets: II. The journal of finance, 46(5), 1575-1617.

Forti, C. A. B., Peixoto, F. M., \& Santiago, W. P. (2009). Hipótese da eficiência de mercado: um estudo exploratório no mercado de capitais brasileiro. Gestão \& Regionalidade (Online), 25(75), 45-56.

French, K. R. (1980). Stock returns and the weekend effect. Journal of Financial Economics, 8(1), 5569. Friedman, M. (1970). The social responsibility of business is to increase its profits. New York, p.

122-124. 
Galdão, A., \& Famá, R. (1998). Avaliação da eficiência na precificação de ações negociadas no Brasil, por teste de volatilidade. Revista de Administração da Universidade de São Paulo, 33(2), 60-68.

Geske, R., \& Roll, R. (1983) The fiscal and monetary linkage between stocks returns and inflation. The journal of Finance, 38(1), 1-33. Gil, A. C. (2007). Como elaborar projetos de pesquisa. 4. ed. São Paulo: Atlas.

Global Sustainable Investiment Alliance - GSIA. Global sustainable investment review. 2014. Recuperado em 19 outubro, 2016 de http:// www.gsi-alliance.org

Hansen, B. E. (2016). Econometrics. Wisconsin: University of Wiscosin.Jonsson, R.; Radeschnig, J. (2014). From Market Efficiency to Event Study Methodology: an Event Study of Earnings Surprises on Nasdaq OMX Stockholm. Bachelor Thesis in Economics, Mälardalen University, Västerås, Sweden.

Kauark, F. S.; Manhães, F. C.; Medeiros, C. H. (2010). Metodologia da pesquisa: um guia prático. Bahia: Via Litterarum.

Lyon, T. P., \& Shimshack, J. P. (2015). Environmental disclosure: Evidence from Newsweek's green companies rankings. Business \& Society, 54(5), 632-675.

MacKinlay, A. C. (1997). Event studies in economics and finance. Journal of economic literature, 35(1), 13-39.

Madorran, C., \& Garcia, T. (2016). Corporate social responsibility and financial performance: the Spanish case. Revista de Administração de Empresas, 56(1), 20-28.

Marques, S., Ahlfeldt, R., Cruz, J. A. W., \& Silva, W. V. (2015). Análise de anomalia da hipótese dos mercados eficientes à luz das finanças comportamentais. Revista da Faculdade de Administração e Economia, 6(2), 33-50.

Martins Júnior , J. (2011). Como escrever trabalhos de conclusão de curso. Petrópolis: Vozes.

Mitcham, C. (1995). The concept of sustainable development: its origins and ambivalence. Technology in society, 17(3), 311-326.

Murguia, J. M., \& Lence, S. H. (2015). Investors' Reaction to Environmental Performance: A Global Perspective of the Newsweek's "Green Rankings". Environmental and Resource Economics, 60(4), 583-605.

Mussa, A., Yang E., Trovão, R., \& Famá, R. (2008). Hipótese de mercados eficientes e finanças comportamentais: as discussões persistem. FACEF Pesquisa-Desenvolvimento e Gestão, 11(1), 5-17.

Mutezo, A. (2014). Socially responsible investment and financial performance: evidence from the Johannesburg securities exchange. Banks and Bank Systems, 9(3), 120-128.

Oberndorfer, U., Schmidt, P., Wagner, M., \& Ziegler, A. (2013). Does the stock market value the inclusion in a sustainability stock index? An event study analysis for German firms. Journal of Environmental Economics and Management, 66(3), 497-509.

Oliveira, D. M., Almeida, C. A. S., Rocha, L. A., Tortato U., \& Silva, W. V. (2015). Relação entre responsabilidade social corporativa e desempenho financeiro das empresas brasileiras do setor energético. Revista Uniabeu, 8(18), 17-32.

Revelli, C., \& Viviani, J. L. (2015). Financial performance of socially responsible investing (SRI): what have we learned? A meta-analysis. Business Ethics: A European Review, 24(2), 158-185.

Rocha, H. M., \& Delamaro, M. C. (2011). Abordagem metodológica na análise de dados de estudos não-paramétricos, com base em respostas em escalas ordinais. GEPROS: Gestão da Produção, Operações e Sistemas, 6(3), 77-92.Schaeffer, R., Borba, B. S., Rathmann, R., Szklo, A., \& Branco, D. A. C. (2012). Dow Jones sustainability index transmission to oil stock market returns: a Garch approach. Energy, 45(1), 933-943.

Serpa, D. A. F., \& Fourneau, L. F. (2007). Responsabilidade social corporativa: uma investigação sobre a percepção do consumidor. Revista de Administração Contemporânea, 11(3), 83-103.

Silva, N. E. F., Coelho, P. F. C., \& Cavalcante, C. E. (2016). Isomorfismo e sustentabilidade: análise nas empresas do setor elétrico brasileiro. Exacta, 14(2), 251-268.

Soares, R. O., Rostagno, L. M., \& Soares, K. T. C. (2002). Estudo de evento: o método e as formas de cálculo do retorno anormal. Anais do Encontro Nacional dos Programas de Pós Graduação em Administração. Salvador, BA, Brasil, 22.

Soppe, A. (2009). Sustainable finance as a connection between corporate social responsibility and social responsible investing. Indian School of Business WP Indian Management Research Journal, $1(3), 13-23$. 
United States Social Investment Forum - USSIF. SRI Basics. Recuperado em 30 maio, 2016 de $<$ http://www.ussif.org/sribasics>

Wang, Y. S., \& Chen, Y. J. (2015). Corporate social responsibility and financial performance: Event study cases. Journal of Economic Interaction and Coordination, 10(1), 1-27. 